\title{
In Vivo Application of Proton-Electron Double-Resonance Imaging
}

\author{
Shun Kishimoto, Murali C. Krishna, Valery V. Khramtsov, ${ }^{2,3}$ Hideo Utsumi, and David J. Lurie ${ }^{5}$
}

\begin{abstract}
Significance: Proton-electron double-resonance imaging (PEDRI) employs electron paramagnetic resonance irradiation with low-field magnetic resonance imaging so that the electron spin polarization is transferred to nearby protons, resulting in higher signals. PEDRI provides information about free radical distribution and, indirectly, about the local microenvironment such as partial pressure of oxygen $\left(\mathrm{pO}_{2}\right)$, tissue permeability, redox status, and acid-base balance.

Recent Advances: Local acid-base balance can be imaged by exploiting the different resonance frequency of radical probes between $\mathrm{R}$ and $\mathrm{RH}^{+}$forms. Redox status can also be imaged by using the loss of radical-related signal after reduction. These methods require optimized radical probes and pulse sequences.

Critical Issues: High-power radio frequency irradiation is needed for optimum signal enhancement, which may be harmful to living tissue by unwanted heat deposition. Free radical probes differ depending on the purpose of PEDRI. Some probes are less effective for enhancing signal than others, which can reduce image quality. It is so far not possible to image endogenous radicals by PEDRI because low concentrations and broad line widths of the radicals lead to negligible signal enhancement.

Future Directions: PEDRI has similarities with electron paramagnetic resonance imaging (EPRI) because both techniques observe the EPR signal, directly in the case of EPRI and indirectly with PEDRI. PEDRI provides information that is vital to research on homeostasis, development of diseases, or treatment responses in vivo. It is expected that the development of new EPR techniques will give insights into novel PEDRI applications and vice versa. Antioxid. Redox Signal. 28, 1345-1364.
\end{abstract}

Keywords: Overhauser MRI, OMRI, PEDRI, free radical, imaging

Introduction:

$\mathbf{P}$ Roton-electron double-Resonance imaging (PEDRI), also known as Overhauser-enhanced magnetic resonance imaging (OMRI), is an imaging modality with similarities to MRI as well as to Electron Paramagnetic Resonance Imaging (EPRI). It is usually carried out at extremely low magnetic fields of $10-40 \mathrm{mT}$ corresponding to proton Larmor frequencies of $0.5-2 \mathrm{MHz}$ and electron Larmor frequencies of 300-1200 MHz. At such low magnetic fields, the polarization of the ${ }^{1} \mathrm{H}$ spin states is small, making it difficult to generate MR images with a useful signal-to-noise ratio (SNR).
However, in the presence of paramagnetic species with narrow electron paramagnetic resonances (EPRs), application of electromagnetic radiation at the resonance frequency of the electron spins (typically at radio frequency) significantly enhances the nuclear polarization to a theoretical maximum of 330 -fold (half of $\gamma \mathrm{e} / \gamma p=659$ ), where $\gamma \mathrm{e}$ and $\gamma \mathrm{p}$ are, respectively, the electron and proton gyromagnetic ratios. Under these circumstances, due to dipolar coupling between the unpaired electrons and the solute (water) protons in the system, polarization is transferred to nearby protons, creating much larger population differences between the nuclear spin states, in turn leading to a large increase in signal intensity $(48,49,79,114)$.

\footnotetext{
${ }^{1}$ Radiation Biology Branch, Center for Cancer Research, National Cancer Institute, Bethesda, Maryland.

${ }^{2}$ In Vivo Multifunctional Magnetic Resonance center and ${ }^{3}$ Department of Biochemistry, Robert C. Byrd Health Sciences Center, West Virginia University, Morgantown, West Virginia.

${ }^{4}$ School of Pharmaceutical Sciences, The University of Shizuoka, Shizuoka, Japan.

${ }^{5}$ School of Medicine, Medical Sciences \& Nutrition, University of Aberdeen, Aberdeen, United Kingdom.
} 
This method is known as the Overhauser effect, or sometimes as liquid-state Dynamic Nuclear Polarization (DNP). The saturation of electrons is carried out for a duration in the order of the proton spin lattice relaxation time, after which the ç detection and spatial encoding follow immediately, resulting in a significant enhancement of the proton signals. Images with useful SNR can be acquired in such a manner even at such low magnetic fields. Further, PEDRI is effectively an indirect form of EPRI in the sense that the enhancement of proton signals is proportional to the concentration of the paramagnetic system and the degree of saturation of the EPR system. In a PEDRI image, regions of the sample containing free radicals "light up" due to the Overhauser-enhanced proton nuclear magnetic resonance (NMR) signal, revealing the location of the free radical. This review covers the topic of PEDRI from the historical background to various preclinical applications of the technique, including partial pressure of oxygen $\left(\mathrm{pO}_{2}\right)$ mapping, permeability mapping, redox mapping, and $\mathrm{pH}$ mapping.

\section{Historical Background}

DNP of nuclear spin states was predicted by Albert Overhauser in 1953 (100), a technique that became known as the Overhauser effect. In the theory, saturating the electron spin resonance of a paramagnetic species will significantly enhance the polarization of surrounding nuclear spins. This prediction was confirmed by Carver and Slichter in 1956 who had been researching the electron spin resonance of lithium (20). In the process of experimental verification of the Overhauser effect, they concluded that the effect could be observed in any system in which the nuclear relaxation was dominated by a coupling to electrons in which the nuclear spin flip requires a simultaneous electron flip. To further verify these conclusions, they successfully performed experiments on systems of ${ }^{7} \mathrm{Li},{ }^{23} \mathrm{Na}$, and even ${ }^{1} \mathrm{H}$ (20). The Nuclear Overhauser Effect (NOE) is an extension of the Overhauser effect explained with experimental observation by Kaiser in 1962, demonstrating polarization transfer from one population of nuclear spins to another via cross relaxation (65). The NOE is utilized in the field of NMR spectroscopy, including its use to determine the three-dimensional structure of complex molecules. Here, we focus on the Overhauser effect where electron spin polarization is transferred to ${ }^{1} \mathrm{H}$ polarization with subsequent MRI to reveal the localized concentration of free radicals.

The ability to image the distribution of paramagnetic solutions in vivo has many potential uses in biology and medicine. EPRI, which uses methods analogous to those employed in NMR imaging, has been developed with considerable effort (8, $9,31,38,85)$. However, EPR was typically restricted to small samples $(\sim 50 \mathrm{~mm})$ because of the relatively large line widths ( $\sim \mathrm{MHz})$ and the strong gradients necessary to achieve useful spatial resolution. Endogenous free radicals are present in small quantities and are often short-lived with a very low steady-state concentration. Therefore, it is necessary to introduce free radicals as "probes" into the living system that should be biocompatible, stable during the measurement, and nontoxic. Oxygen concentration in tissues can be deduced via its linebroadening effect on the EPR spectrum of injected free radical.

To image paramagnetic species such as injected free radicals in larger-sized biological systems and animals, Lurie et al. developed in 1988 an imaging technique that combines proton NMR imaging with the Overhauser effect, called PEDRI, which is also known as OMRI (79). The main difference between PEDRI and EPRI is that the enhanced proton signal is observed in PEDRI, whereas the electron signal from the free radical probe is observed directly in EPRI. Unlike EPRI, large sample sizes with higher resolution can be achieved in PEDRI because proton resonances are detected after enhancement by the Overhauser effect. The terms $P E D R I$ and $O M R I$ represent one and the same technique; throughout this article, we will use PEDRI.

Under appropriate conditions, EPR irradiation causes a transfer of polarization from the unpaired electrons to the proton nuclei of tissue water, increasing the intensity of the ${ }^{1} \mathrm{H}$ NMR signal. The enhancement of the NMR signal can be described by the enhancement factor, E, given by:

$$
\mathrm{E}=\mathrm{A}_{\mathrm{Z}} / \mathrm{A}_{0}
$$

where $A_{Z}$ and $A_{0}$ are the NMR signals with and without EPR irradiation, respectively. The enhancement can be described by the following relationship:

$$
\mathrm{E}=1-\rho f(\mathrm{~s} / \mathrm{n})(\gamma \mathrm{e} / \gamma \mathrm{p})
$$

where $\rho$ is the coupling factor $(-1 \leq \rho \leq 1 / 2$, with $\rho=1 / 2$ for dipole-dipole interactions), $\mathrm{f}$ is the leakage factor $(0 \leq$ $\mathrm{f} \leq 1), \mathrm{s}$ is the saturation factor $(0 \leq \mathrm{s} \leq 1), \mathrm{n}$ is the number of hyperfine lines in the EPR spectrum $(n=3$ for a typical nitroxide-free radical), and $\gamma \mathrm{e}$ and $\gamma \mathrm{p}$ are the electron and nuclear gyromagnetic ratios (for experiments involving protons, the ratio [ $\gamma \mathrm{e} / \gamma \mathrm{p} \approx 659])$. Equation [2] assumes that only one EPR resonance is irradiated at a time (81).

Figure 1 shows the capability of PEDRI to provide ${ }^{1} \mathrm{H}$ images at low magnetic fields and to assess the influence of

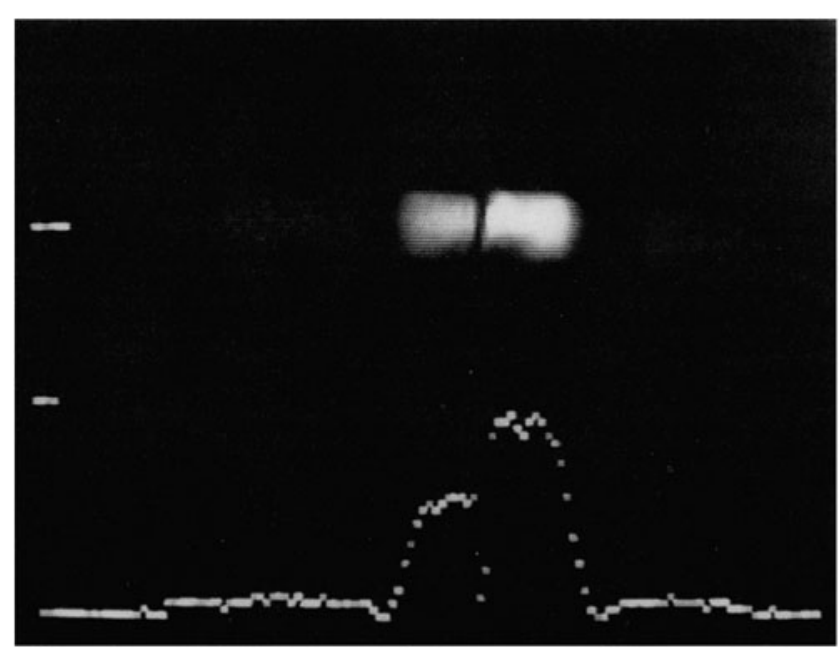

FIG. 1. PEDRI magnitude image of two phantom tubes containing air-equilibrated (left) and nitrogen-equilibrated (right) $2.5 \mathrm{~m} M$ TEMPOL solution dissolved in water (79). Due to different oxygen concentration, the magnitude of enhancement is higher in the right phantom tube. Calculated enhancement factors were -6.9 (left) and -9.8 (right). Reprinted by permission from Lurie et al. (79). PEDRI, proton-electron double-resonance imaging; TEMPOL, 4Hydroxy-2,2,6,6-tetramethylpiperidine-1-oxyl. 
dissolved oxygen on the enhancement (79). Two identical phantom tubes were filled with $2.5 \mathrm{~m} M$ 4-hydroxy-2,2,6,6tetramethylpiperidine-1-oxyl (TEMPOL) solution dissolved in water, one of which had been equilibrated with nitrogen by bubbling the gas through the phantom and the other with air. The nitrogen-equilibrated phantom exhibited a $40 \%$ greater enhancement than the air-equilibrated one with calculated enhancement factors of -6.9 (left) and -9.8 (right). This effect occurs because EPR resonances of spin labels are differentially broadened in the presence of dissolved oxygen $(13,46,100,117)$. A broad EPR line is more difficult to saturate; thus, the observed enhancement factor for a given magnetic field strength is reduced. PEDRI images have been obtained with TEMPOL concentrations as low as $0.3 \mathrm{~m} M$, which is, nevertheless, more than three orders of magnitude higher than the concentration of intrinsic radicals (84).

\section{Field Cycling}

To make PEDRI applicable for in vivo experiments by avoiding excessive sample heating due to high power of EPR irradiation, field cycling (FC) was introduced in the pulse sequence of image acquisition, which greatly reduces the applied field strength during EPR irradiation (82). In FCPEDRI, the magnetic field applied to the sample is changed throughout the experiment. Figure 2 shows the pulse sequence of FC-PEDRI. The EPR irradiation is applied at low magnetic field strength (at a correspondingly low frequency), during which the Overhauser polarization transfer alters the proton magnetization (Evolution Period). The magnetic field is then increased rapidly for the detection period, during which the NMR detection pulse(s) and magnetic field gradients are applied (Detection Period). Applying the EPR irradiation at a low field decreases the EPR frequency and the nonresonant power deposition (which varies approximately as the square of the frequency), allowing larger samples to be used. The optimum EPR frequency as well as evolution field depends on the EPR linewidth of the free radical and on the size of the sample. It has previously been shown that with nitroxide-free radicals and large samples, the optimum frequency is between 30 and $60 \mathrm{MHz}$, corresponding to an
Evolution (EPR) field of $\sim 3 \mathrm{mT}$ (78). Detecting the NMR signals at a high field is necessary to increase the SNR of the experiment.

Figure 3 shows FC-PEDRI images of a resolution phantom (B-D); a field-cycled non-PEDRI image (A) is also shown for comparison (82). The center of the phantom consisted of five tubes of internal diameters $15,9,5,4$, and $3 \mathrm{~mm}$ filled with $2 \mathrm{~m} M$ TEMPOL solution. These were enclosed in a cylindrical container of diameter $4 \mathrm{~cm}$ that was filled with water doped with copper sulfate to give the same $T_{1}$ as that of the free radical solution $(650 \mathrm{~ms}$ at $2.5 \mathrm{MHz})$. Fourteen sample tubes with internal diameters of $8 \mathrm{~mm}$ were attached around the outside of the cylinder, with alternate tubes being filled with $2 \mathrm{~m} M$ TEMPOL solution or copper sulfate-doped water. The overall diameter of the phantom was $6 \mathrm{~cm}$, about the size of a small rat. The three FC-PEDRI images were obtained by using EPR irradiation time ( $\mathrm{T}^{\mathrm{EPR}}$ ) values of 750,1000 , and $1500 \mathrm{~ms}$ with a repetition time of $2000 \mathrm{~ms}$, and the average observed enhancement factors were $-4.0,-5.3$, and -7.1 , respectively. The instantaneous power level in the EPR irradiation was approximately $7 \mathrm{~W} / \mathrm{kg}$, whereas the average applied power ranged from 2.7 to $5.3 \mathrm{~W} / \mathrm{kg}$ depending on the pulse sequence timing. In FC-PEDRI, the enhanced versus unenhanced image intensity ratio depends not only on the power of the EPR irradiation but also on the relative timing of the polarization and evolution intervals, and the values of $\mathrm{B}_{0}{ }^{\mathrm{P}}$ and $\mathrm{B}_{0}{ }^{\mathrm{D}}$. At the beginning of the evolution period, the size of the magnetization depends on the length of the polarization period compared with the sample's $\mathrm{T}_{1}$ at $\mathrm{B}_{0}{ }^{\mathrm{P}}$. During the evolution period, the magnetization decays at a rate determined by the sample's $\mathrm{T}_{1}$ at $\mathrm{B}_{0}{ }^{\mathrm{E}}$. Meanwhile, the magnetization in regions of the sample containing free radical increases at a rate depending on $\mathrm{T}_{1}$ toward an equilibrium value that depends on the EPR irradiation power. The results from FC-PEDRI show that free radicals can be imaged with greater resolution than with EPR, which typically relies on projection reconstruction.

In vivo experiments using FC-PEDRI have been reported. Figure 4 shows images from an in vivo experiment using the nitroxide radical proxyl carboxylic acid (PCA) in the rabbit (81). An anesthetized rabbit was placed supine with the
FIG. 2. FC-PEDRI pulse sequence, showing magnetic field, field gradient, and waveforms. Reprinted with permission from IOP Publishing from Lurie et al. (81). (C) Institute of Physics and Engineering in Medicine. All rights reserved. FC, field cycling.

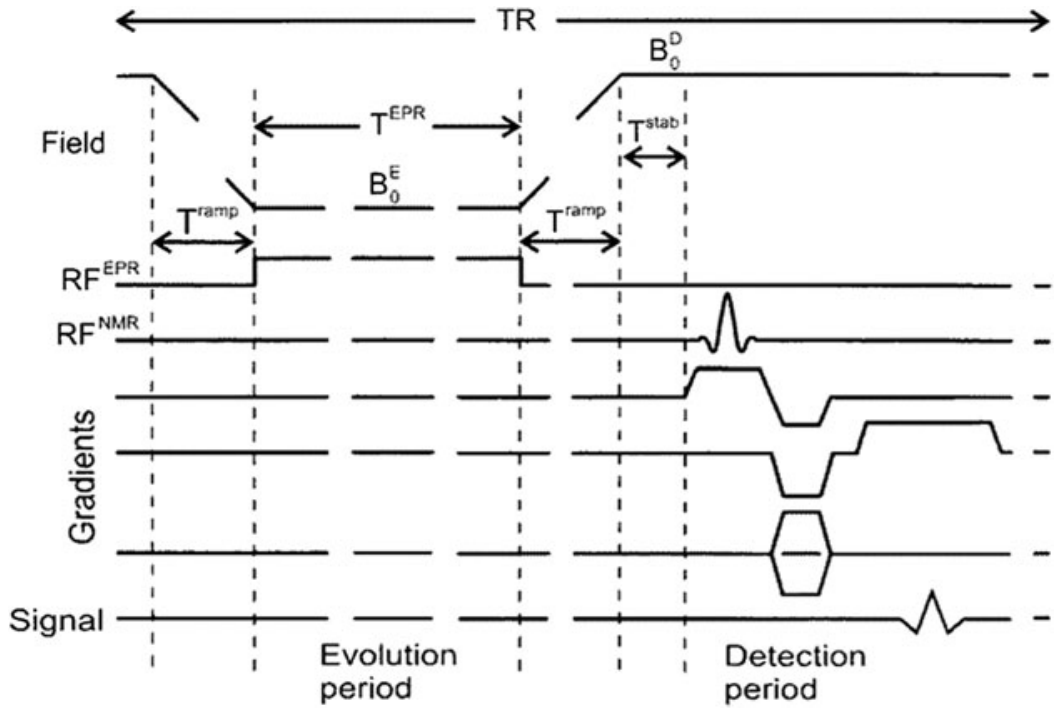



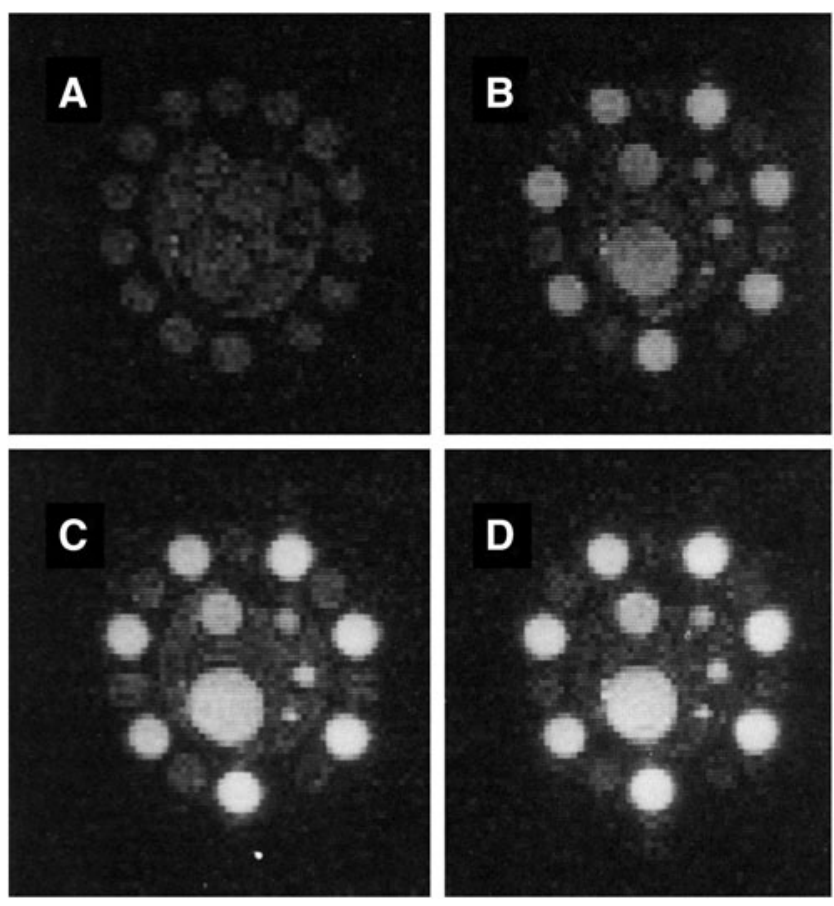

FIG. 3. Images of phantom containing $2 \mathrm{~m} M$ TEMPOL solution and copper sulfate-doped water. Images are $64 \times 64$ sections of original $128 \times 128$ images, which had $15 \mathrm{~cm}$ field of view, $15 \mathrm{~mm}$ slice thickness. All images are field-cycled, with $\mathrm{B}_{0}{ }^{\mathrm{P}}=\mathrm{B}_{0}{ }^{\mathrm{D}}=0.01 \mathrm{~T}, \mathrm{~B}_{0}{ }^{\mathrm{E}}=0.0051 \mathrm{~T}$, saturation-recovery NMR sequence with $\mathrm{TR}=2000 \mathrm{~ms}$, four averages. Image $(\mathbf{A})$ has $\mathrm{T}^{\mathrm{EPR}}=1000 \mathrm{~ms}$, no EPR irradiation. Images (B-D) have EPR irradiation at $160 \mathrm{MHz}$, power $1 \mathrm{~W}$. Image (B) has $\mathrm{T}^{\mathrm{EPR}}=750 \mathrm{~ms}$; observed enhancement factor $\mathrm{E}=-4.0$. Image $(\mathbf{C})$ has $\mathrm{T}^{\mathrm{EPR}}=1000 \mathrm{~ms} ; \mathrm{E}=-5.3$. Image $(\mathbf{D})$ has $\mathrm{T}^{\mathrm{EPR}}=1500 \mathrm{~ms} ; \mathrm{E}=-7$. I. Reprinted with permission from Lurie et al. (82). T ${ }^{\mathrm{EPR}}$, EPR irradiation time. NMR, nuclear magnetic resonance; EPR, electron paramagnetic resonance.

kidneys placed centrally, and an FC-PEDRI image was collected. The free radical probe was then administered, and a series of FC-PEDRI images was obtained at approximately 6 min intervals. Images were obtained by using both $64 \times 64$ and $128 \times 128$ matrices. In both cases, the image parameters were: field of view $15 \mathrm{~cm}$, slice thickness $3 \mathrm{~cm}, \mathrm{TR}=1000 \mathrm{~ms}$, $\mathrm{T}^{\mathrm{EPR}}=300 \mathrm{~ms}, \mathrm{~T}^{\mathrm{ramp}}=40 \mathrm{~ms}, \mathrm{~T}^{\mathrm{stab}}=10 \mathrm{~ms}$, EPR frequency $51.0 \mathrm{MHz}$, and $\mathrm{B}_{0}{ }^{\mathrm{E}}=3.05 \mathrm{mT}$. The forward power to the birdcage resonator was approximately $300 \mathrm{~W}$, and the power absorbed in the animal can be estimated as $130 \mathrm{~W}$ by using the loaded and unloaded Q factors (measured to be 193 and 346 , respectively). Considering the duty cycle of the EPR irradiation ( $300 \mathrm{~ms}$ in $2000 \mathrm{~ms}$, or $15 \%$ ), the average specific absorption rate (SAR) in the $2.2 \mathrm{~kg}$ animal is $9 \mathrm{Wkg}^{-1}$. Considering the delays between consecutive image collections, the overall SAR was only $3 \mathrm{~W} \mathrm{~kg}^{-1}$. Although this is still higher than desirable, the experiment successfully demonstrated that FC-PEDRI of a moderately large animal was possible without overheating the animal due to nonresonant absorption of the EPR irradiation. Figure 4 shows "without EPR," "with EPR," and "difference" transaxial images through the animal's abdomen obtained 2 min after injection of the nitroxide-free radical. As reported in the rat (111), PCA is cleared through the rabbit's kidneys, and this
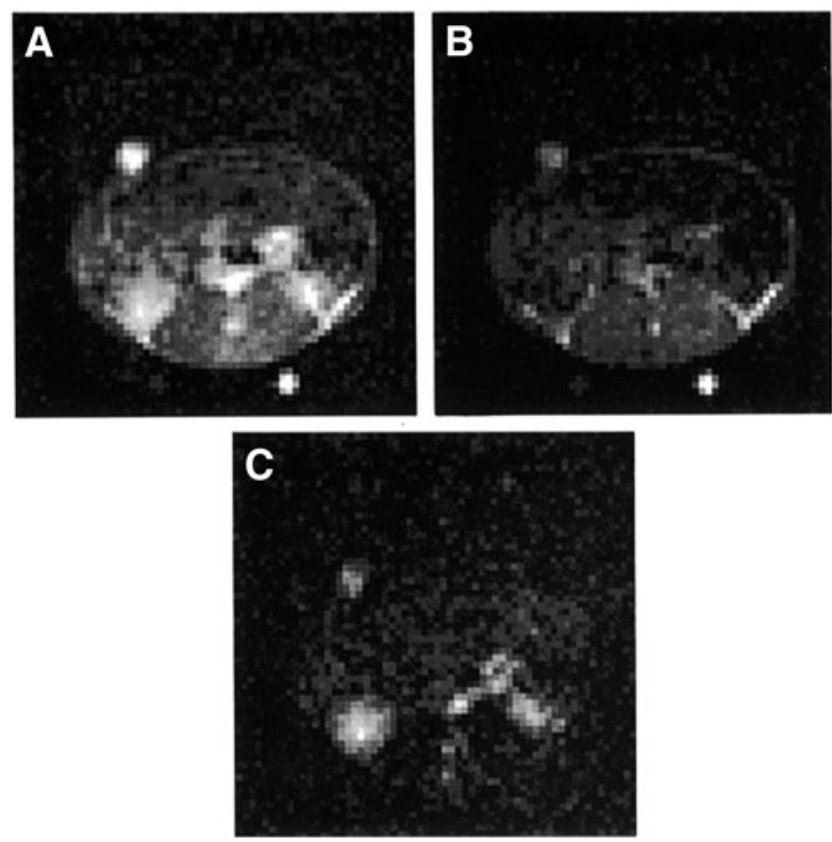

FIG. 4. Trans-axial images through abdomen of anesthetized rabbit after injection of PCA nitroxide-free radical. (A) "without EPR" image, (B) "with EPR" image, (C) "difference" image. The difference image shows the animal's kidneys and major blood vessels. The high-intensity region above the animal is a reference vial containing $1 \mathrm{mM}$ PCA solution. Vials containing $\mathrm{CuSO}_{4}$ solution are seen below the animal in $(\mathbf{A}, \mathbf{B})$; these are used to aid positioning. Reprinted with permission of IOP Publishing from Lurie et al. (81). (C) Institute of Physics and Engineering in Medicine. All rights reserved. PCA, proxyl carboxylic acid.

can be seen clearly in the difference image, together with major blood vessels. The SNR in the difference image was measured to be $14 \pm 1.5$ (81).

\section{Optimization of Probes for PEDRI}

The feasibility of in vivo application of PEDRI had been intensively researched by several groups in the literature in the 1990s. However, nitroxides used as contrast media in the studies until the late 1990s were not optimized enough to produce morphological images at $\sim 10 \mathrm{mT}(3,47,79,82)$. The nitrogen nucleus has a spin 1 and splits the single transition into three transitions. So, when one transition is irradiated, only $1 / 3$ of the possible enhancement is available and high power is needed to saturate it due to the short relaxation time. Both these factors result in restricted enhancement and, consequently, a low SNR in the resulting images. In addition, the short pharmacological half-lives of these species further limited their use for PEDRI research. To improve the SNR of in vivo PEDRI, triarylmethyl or trityl radicals (TAM), paramagnetic substances with single narrow lines and a long relaxation time were synthesized as probes $(4,17,44,105,131$, 134). Figure 5A shows the chemical structural formula of TAM, and Figure 5B illustrates the case of $\Phi$ when it is Ox63. The narrow line without splitting was realized by designing the location of unpaired electron more than five bonds away from magnetic nuclei. The carboxyl group in $\Phi$ makes TAM 


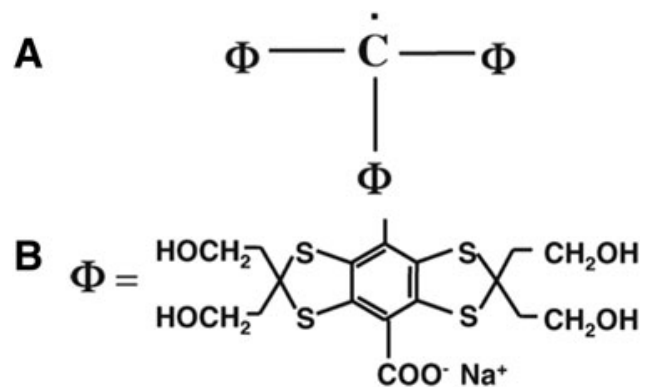

FIG. 5. (A, B) Chemical structure of TAM. Reprinted with permission from Krishna et al. (75). TAM, trityl radical.

highly soluble. TAM distributes in extracellular space due to its negative charge. TAM also has other characteristics that are needed for EPR probe (stability, low toxicity, long in vivo half-lives, and $\mathrm{pO}_{2}$-dependent EPR line widths).

By combining these probes with improved imaging hardware and pulse sequences, significant improvements in the quality of morphological images in rats were reported in 1998 (44). That study also showed that TAM behaved pharmacokinetically as an extravascular, extracellular MR contrast medium, which indicated that it remains mainly within the vascular bed during the first few re-circulations in the body. In vivo images from another study are illustrated in Figure 6, which shows the difference between unenhanced MRI and PEDRI by using TAM in a mouse at $20 \mathrm{mT}$. The PEDRI image displays significantly higher SNR, though both images were taken in comparable times. The imaging parameters are listed in the figure caption (83).

Figure 7 also shows a set of coronal FC-PEDRI images (EPR-on, EPR-off and difference, Fig. 7A-C respectively) of a $172 \mathrm{~g}$ rat, 51 min after injection of a dose of TAM; imaging parameters are listed in the figure caption (80). These images illustrate the advantage of using a relatively high-detection magnetic field $(0.45 \mathrm{~T})$ to boost the overall SNR, with an attendant increase in sensitivity and image quality. A slice thickness of $30 \mathrm{~mm}$ was used to visualize the injected free radicals independent of its anterior-posterior position within the animal. In the difference image, the animal's kidneys and bladder can clearly be seen. The ureters are also clearly visible, even though they represent only a small fraction of the volume of a voxel (the voxel dimensions are 30/0.8/ $0.8 \mathrm{~mm}$ ). It is also noteworthy that by using TAM the imaging of renal excretion has improved substantially from Figure 4 using PCA.

\section{$\mathrm{pO}_{2}$ Mapping with PEDRI}

Oxygen supply and diffusion into tissues is necessary for cellular function (19). The oxygen $\mathrm{pO}_{2}$, which is a key measure of the physiological state of an organ, results from the balance between oxygen delivery and its consumption. Oxygen transported by red blood cells is delivered dependent on the metabolic requirements and functional status of each organ. Tissue oxygenation is severely disturbed during pathological conditions such as cancer, diabetes, coronary heart disease, stroke, etc., which are associated with a decrease in $\mathrm{pO}_{2}$ (19). Several different techniques have been developed to quantify the concentration of oxygen. Invasive methods involve oxygen sensitive electrodes such as the a
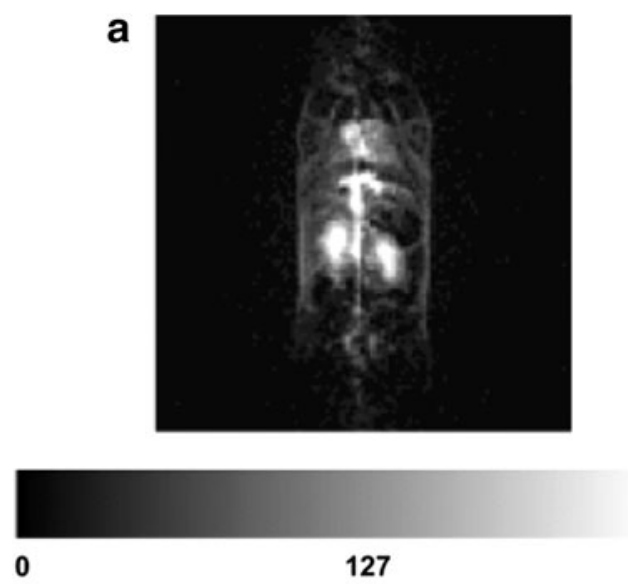

255

b
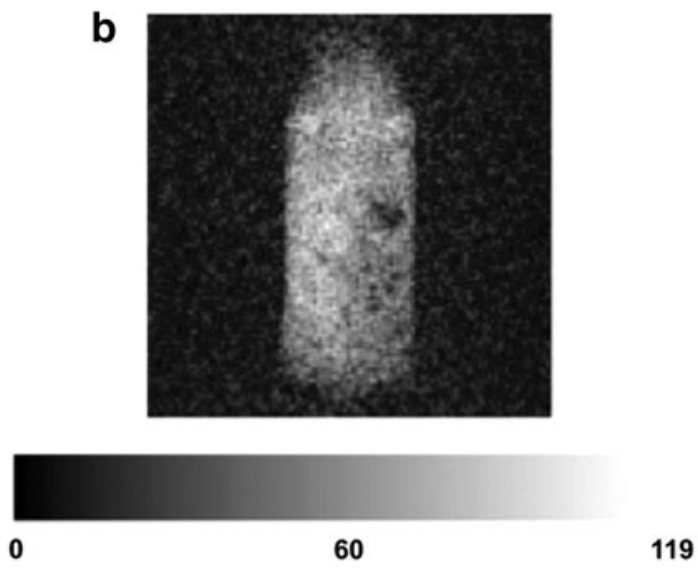

FIG. 6. PEDRI (a) and MRI (b) images of an aesthetized mouse. (a) Projective coronal gradient-echo PEDRI image of an anesthetized $30-\mathrm{g}$ mouse $3 \mathrm{~min}$ after administration of i.v. dose of $0.66 \mathrm{mmol} / \mathrm{kg}$ TAM. Image shows an enhancement of -5 in the kidneys and major blood vessels. Image parameters: matrix size $128 \times 128$; FOV $8 \times 8 \mathrm{~cm}$; TR $1200 \mathrm{~ms}$; TE $12 \mathrm{~ms}$; EPR irradiation time $400 \mathrm{~ms}$; NEX 1; EPR irradiation at $564 \mathrm{MHz}$. The applied EPR irradiation power at the resonator was $3 \mathrm{~W}$ with $26 \%$ absorbed by the 30 -gm mouse, resulting in an SAR of $7.4 \mathrm{~W} / \mathrm{kg}$ during the 2min 40-s acquisition time. (b) Image of the same animal without EPR irradiation (other parameters are identical). Reprinted with permission from Lurie et al. (83).

Clark electrode $(51,54)$ or the Eppendorf electrode (127, 130). As noninvasive methods, the blood oxygenation leveldependent MRI techniques $(16,96,99)$ where a $\mathrm{T}_{2}{ }^{*}$-sensitive gradient echo pulse sequence is used to visualize the ratio between oxy/deoxy-hemoglobin and nonhydrogen nuclei such as ${ }^{17} \mathrm{O}(89,97,136)$ or ${ }^{19} \mathrm{~F}$ MR images $(88,101,107)$ where the oxygen concentration is reflected in the signal intensity of the image are available.

The electron spin relaxation times are mainly determined by self-broadening and oxygen-induced relaxation $(1,35,39$, $40,67,118,120,137)$. In PEDRI, the presence of $\mathrm{O}_{2}$ shortens the relaxation times and, consequently, results in the decreased transfer of polarization to nuclear spins during the EPR irradiation. Variations in the concentration of the unpaired electron substance can also influence the electron spin relaxation times in the same way. Hence, the signal intensity of PEDRI can be calculated by using both oxygen concentration and 
A

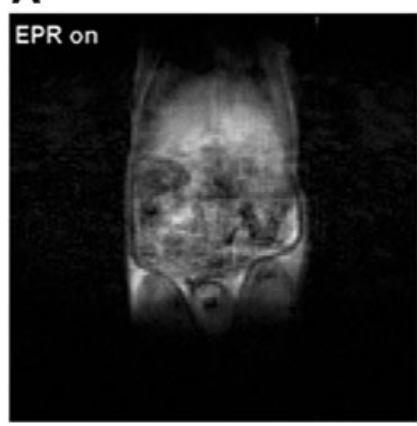

B

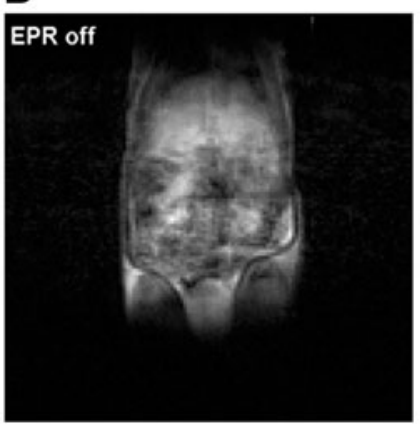

C

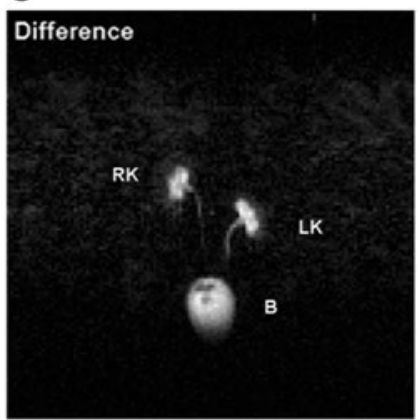

FIG. 7. Images of 172-g anesthetized rat, $51 \mathrm{~min}$ after injection of $0.58 \mathrm{mmol} / \mathrm{kg}$ iv dose of TAM. (A) Image acquired with EPR irradiation; (B) image acquired without EPR irradiation; (C) difference image; labels: RK—right kidney, LKleft kidney, B-bladder. Acquisition parameters: $128 \times 128$ matrix; field of view, $100 \times 100 \mathrm{~mm}$; slice thickness, $30 \mathrm{~mm}$; NEX 1; TR, $1050 \mathrm{~ms}$; $\mathrm{T}^{\mathrm{EPR}}, 400 \mathrm{~ms} ; \mathrm{B}_{0}^{\mathrm{E}}, 3.30 \mathrm{mT}$; EPR irradiation, $93.1 \mathrm{MHz}, 15 \mathrm{~W}$ applied power. Reprinted with permission from Lurie et al. (80).

concentration of radical probe on the relaxation rates. Thus, in vivo oximetry is one of the most straightforward and useful applications of PEDRI (4, 32, 75, 79, 92). EPR methods (both spectroscopic and imaging) are also employed to obtain oxygen information. In EPRI, the spatial as well as the spectral information of the exogenously administered spin probes is obtained. Therefore, EPRI present the in vivo visualization of the spin probes but without complementary anatomical information. In contrast, MRI is a well-established modality that gives superior anatomical information. PEDRI uses the Overhauser effect, thereby indirectly detecting the EPR signal. After the EPR irradiation, using standard MR-imaging techniques, distribution of the probe and the oxygen concentration near the probe is visualized in PEDRI $(4,45,117,128)$. In vivo applications of PEDRI oximetry have been demonstrated, for example by Golman et al. (45).

In the oncology field, approximately one-third of human tumors evaluated for oxygen status have shown significant oxygen deficiency. Oxygen deficiency increases the tumor's resistance toward cancer treatment modalities, including radiation and chemotherapy $(25,52,53,55,104,115,126)$. In addition, hypoxic microenvironments in tumors are known to promote processes driving malignant progression, such as angiogenesis, elimination of p53 tumor suppressor activity, genetic instability, and metastasis $(42,52,94)$. An understanding of tumor hypoxia could lead to the discovery of diagnostic and prognostic markers for malignant progression, discovery of novel therapeutic targets, and the development of new constructs for gene therapy applications in human cancer. Therefore, oximetry by PEDRI, which is a noninvasive and real-time measurement, is of importance in preclinical research. Since PEDRI also provides a quantitative measurement, it is possible to track the change in oxygenation kinetics over days.

Figure 8 shows the enhancement of proton signal by the Overhauser effect in an SCC VII tumor-bearing mouse (right hind leg) by using two different EPR saturating power levels (75). Electron spin-density images and oxygen images can be obtained from these images. These oxygen images were verified by a direct comparison with Eppendorf electrode measurement. The $\mathrm{pO}_{2}$ images of the tumor (Fig. 8B) show distinct intra-tumor heterogeneity with a gradation of oxygen concentration. The $\mathrm{pO}_{2}$ values range from hypoxic to normoxic values $(\sim 50 \mathrm{mmHg})$ and are comparable with tumor $\mathrm{pO}_{2}$ values reported in using different invasive methods. The imaging times ranged between 4 and $8 \mathrm{~min}$, and degradation of $\mathrm{pO}_{2}$ maps caused by animal motion, system instability, and the contrast agent distribution were not observed during this period. This study also shows that PEDRI is capable of monitoring changes in tumor oxygenation in response to the alteration of the breathing gas. In general, mean $\mathrm{pO}_{2}$ values increased during carbogen (95\% oxygen and $5 \%$ carbon dioxide) breathing (Fig. 8C). In particular, the percentage of extremely hypoxic regions $\left(\sim 5 \mathrm{mmHg} \mathrm{pO}_{2}\right)$ decreased $\sim 30 \%$ during carbogen breathing. The result explains the previous reports that the treatment efficiency improved when the tumor was oxygenated either by letting the subject breathe carbogen $(41,50,75,91)$ or when the patient was confined to a hyperbaric oxygen chamber $(2,6$, 14, 22). The results from this study showed the capability of PEDRI in obtaining quantitative maps of in vivo tumor oxygen status noninvasively.

\section{Permeability Mapping with PEDRI}

PEDRI can also be used for simultaneous assessment of tumor $\mathrm{pO}_{2}$ as well as for permeability of the tumor vasculature since the TAM derivative Ox63 is localized to the extracellular, extravascular space in a similar way to the widely used $\mathrm{Gd}^{3+}$ complexes. In normal tissue, there is a balance between proangiogenic and antiangiogenic factors, where mature vasculature with regular architecture ensures adequate supply of nutrients and oxygen. However, in tumors, because of excess proangiogenic factors $(37,95)$, tumor neovasculature is abnormal and chaotic in architecture and has poor structural integrity (61). The lack of adequate pericyte and endothelial coverage results in large vascular pores, causing a marked regional heterogeneity in tumor perfusion and making the tumor vascular hyper-permeable $(29,62)$. As a result, tumor progression is associated with disorganized angiogenesis, which results in inadequate oxygen supply and limited delivery of chemotherapeutics to the tumor $(15,63)$. Thus, noninvasive vascular permeability imaging will be useful in evaluating the tumor vasculature and choosing a treatment strategy. Leakage of exogenously administered tracers from blood vessels can be used to assess the tumor 
FIG. 8. PEDRI images (A) and oxygen images $(B, C)$ of anesthetized $\mathrm{C} 3 \mathrm{H}$ mouse with an implanted SCC tumor. (A) PEDRI with two different EPR irradiation power (right: $3 \mathrm{~W}$, left: $45 \mathrm{~W}$ ). (B) calculated $\mathrm{pO}_{2}$ map based on (A). (C), $\mathrm{pO}_{2}$ images of a $\mathrm{C} 3 \mathrm{H}$ mouse with a $1-\mathrm{cm}$ diameter SCC tumor during air breathing (C, top) and carbogen breathing (C, bottom). The expanded tumor region, given at right, clearly shows heterogeneity in $\mathrm{pO}_{2}$ distribution. Reprinted with permission from Krishna et al. (75). $\mathrm{pO}_{2}$, partial pressure of oxygen. To see this illustration in color, the reader is referred to the web version of this article at www .liebertpub.com/ars

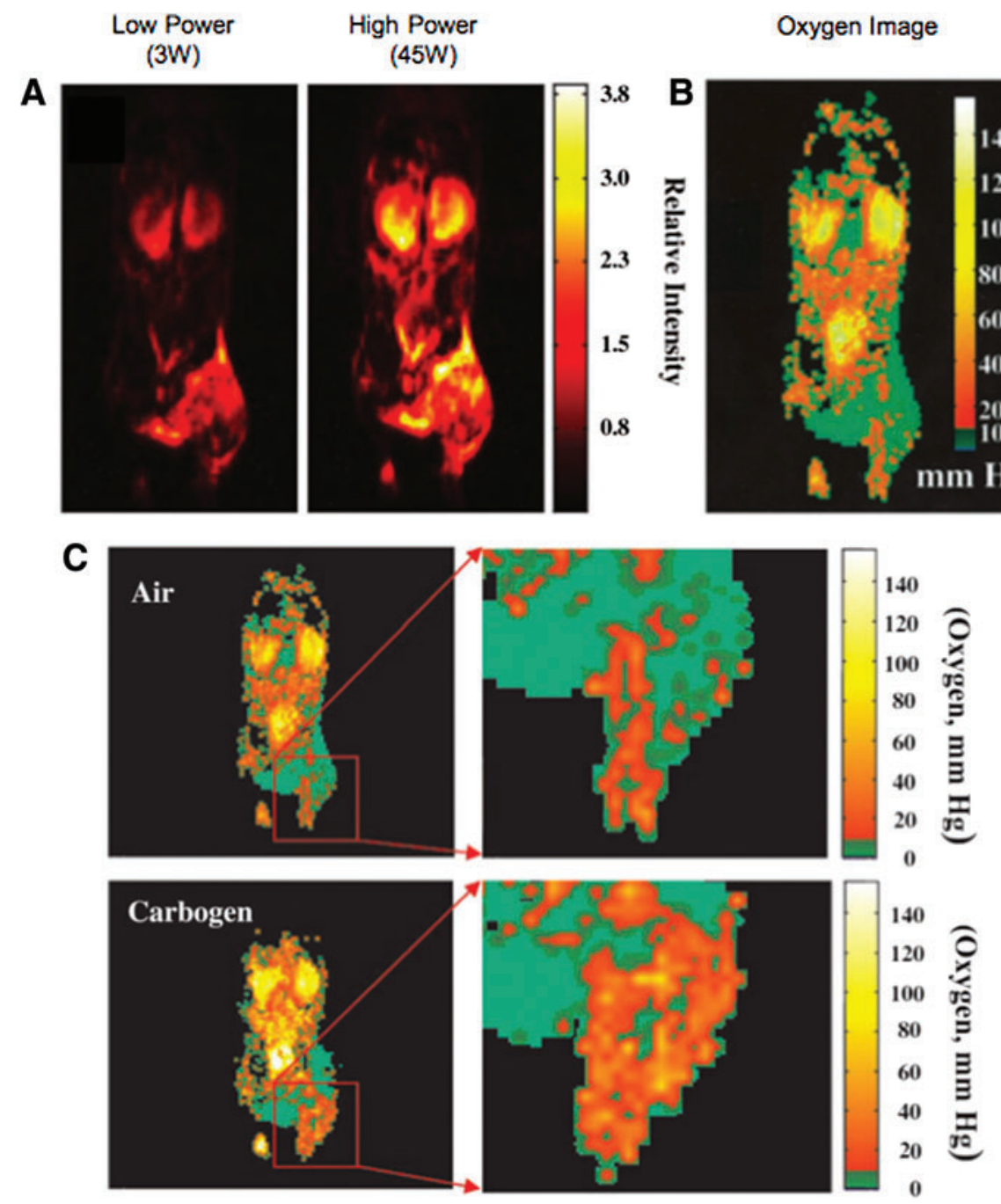

vascular permeability (93). Especially the most commonly used TAM (Ox63: molecular mass 1427) has a molecular mass three times larger than typical gadolinium complexes, which makes its endothelial transport more sensitive to microvascular permeability. With PEDRI, the tissue microvascular permeability imaging can be acquired by using the same datasets that are needed for oximetry. The endothelial transfer coefficient $\mathrm{K}^{\text {trans }}$ was obtained from pharmacokinetics analysis of the contrast agent-induced dynamic signal change that provides useful data to quantify the treatment response in anticancer therapy.

Figure 9 shows the comparison of $\mathrm{K}^{\text {trans }}$ maps of gadolinium-diethylenetriamine pentaacetic acid (Gd-DTPA) and Ox63 with corresponding anatomy images (Fig. 9A) (93). Relatively high $\mathrm{K}^{\text {trans }}$ values were observed globally for Gd-DTPA (Fig. 9B) compared with those for Ox63 (Fig. 9C) in both tumor and normal tissue regions. The result was consistent with its lower molecular mass, making it penetrate easily even through the smaller pores in normal blood vessels $(21,116)$. Therefore, the $\mathrm{K}^{\text {trans }}$ of Gd-DTPA may have larger contributions from blood perfusion in tissue than vascular permeability as reported $(4,116)$. Figure $9 \mathrm{D}$ is a corresponding $\mathrm{pO}_{2}$ map computed from the same PEDRI images for the Ox63 $\mathrm{K}^{\text {trans }}$ map. The inverse relationship between Ox63 $\mathrm{K}^{\text {trans }}$ and $\mathrm{pO}_{2}$ suggested that the leaky and abnormal tumor vasculature is unable to deliver oxygen efficiently to tissue, in agreement with earlier studies using immunohistochemical analyses or oxygen-sensitive electrodes $(28,66)$. This study showed that tumor regions with high vascular permeability ( $\mathrm{K}^{\text {trans }}$ of Ox63) could be hypoxic regardless of blood perfusion as determined by MRI using Gd-DTPA ( $\mathrm{K}^{\text {trans }}$ of Gd-DTPA), suggesting that diffusion-limited hypoxia does not completely determine the oxygen status of tumors (Fig. 9D, F).

\section{Redox Mapping with PEDRI}

Oxidative stress is associated with various diseases such as cancer, cardiovascular disease, Alzheimer's disease (87), Parkinson's disease (64), diabetes mellitus (86), atherosclerosis (113), ischemia reperfusion injury (18), and chronic inflammatory processes (24). The main causative factors are reactive oxygen species, which also act as essential cellular messengers and redox regulators (30). Therefore, developing in vivo noninvasive redox imaging can shed light not only on these pathologies but also on healthy tissue. Utsumi et al. 

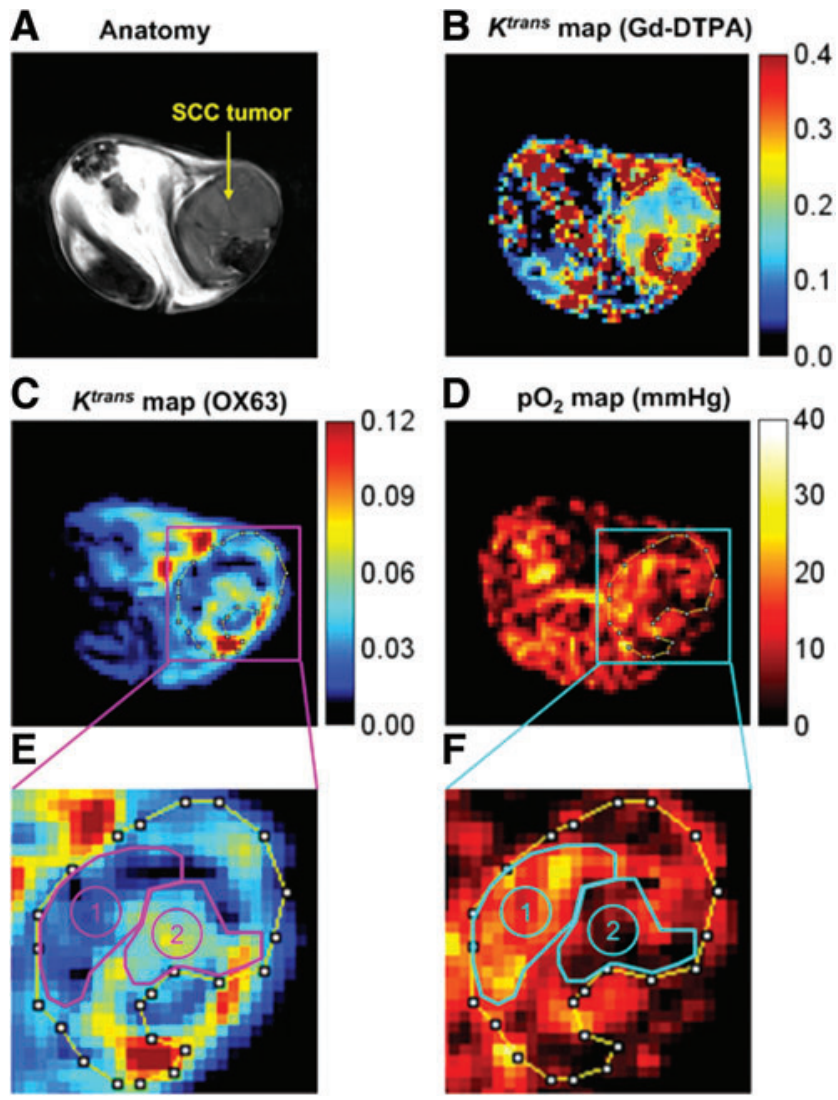

FIG. 9. Comparison of $K^{\text {trans }}$ maps of Gd-DTPA and Ox63 in an SCC tumor. (A) SCC tumor region can be distinguished in a $\mathrm{T}_{2}$-weighted anatomic image by using 7-T MRI. FOV $=32 \mathrm{~mm}$. (B) $\mathrm{K}^{\text {trans }}$ map of Gd-DTPA using 7-T MRI in an SCC tumor-bearing mouse. (C) $\mathrm{K}^{\text {trans }}$ map of Ox63 using PEDRI of the same SCC tumor. Note that PEDRI/Ox63 images were obtained before the 7-T MRI/GdDTPA study. (D) Corresponding $\mathrm{pO}_{2}$ map computed from the same PEDRI images for $\mathrm{K}^{\text {trans }}$ Ox63 map. (E, F) Based on the anatomical image, ROI of SCC tumor was selected and enlarged. Tumor region with low $\mathrm{K}^{\text {trans }} \mathrm{Ox} 63$ values (ROI 1) was relatively oxygenated and normal muscle tissue, and the region with high $\mathrm{K}^{\text {trans }}$ Ox63 values (ROI 2) coincided with hypoxia in $\mathrm{pO}_{2}$ image. Reprinted with permission from Matsumoto et al. (93). Gd-DTPA, gadoliniumdiethylenetriamine pentaacetic acid; ROI, region of interest. To see this illustration in color, the reader is referred to the web version of this article at www.liebertpub.com/ars

utilized the PEDRI technique for redox imaging by using redox-sensitive nitroxyl radical probes in vitro and in vivo by using novel isotope-labeled probes $(5,57,72,90,112,125$, 133). Nitroxyl radicals are known to lose their paramagnetic property via a redox reaction with the hydroxyl radical or the superoxide anion radical (Fig. 10) $(76,129)$. There is a good linear relationship between the generation of hydroxyl radical and the loss of paramagnetism of nitroxyl radical (110). It was also reported that cytochrome $\mathrm{P}-450, \mathrm{NAD}(\mathrm{P}) \mathrm{H}-$ dependent cytochrome $\mathrm{P} 450$ oxidoreductase in microsomes is associated with the loss of paramagnetism of nitroxyl radical and the reduction of nitroxyl in the mitochondorial electron transport system $(58,59,103,124)$. Glutathione and ascorbic acid are also known to support the reduction of nitroxyl radical $(23,121)$, and the 2,2,6,6-ethyl substitution of

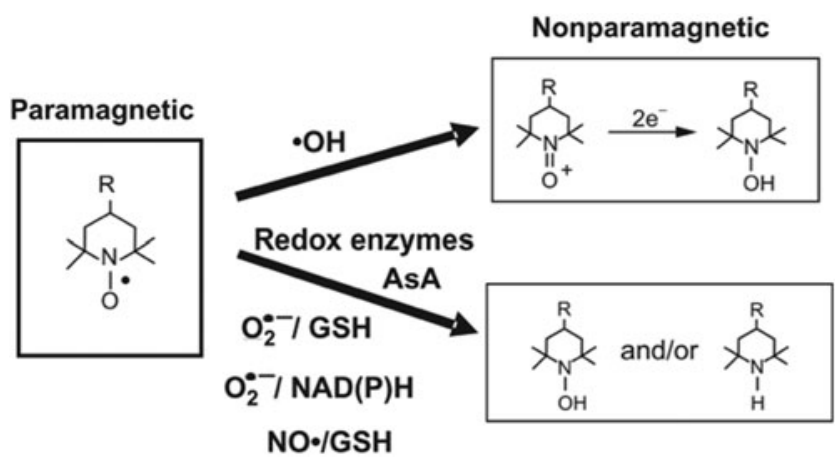

FIG. 10. Reactions that cause loss of nitroxyl radicals. Reprinted with permission from Utsumi and Hyodo (123).

2,2,6,6-Tetramethyl-1-piperidinyloxy (TEMPO) led to resistance toward the reduction with ascorbic acid (71). In such a manner, the nitroxyl radical directly and indirectly reflects the redox state. Hence, analyzing the in vivo conversion rate of the nitroxyl to the diamagnetic state enables visualization of the redox state. Unlike the chemically stable TAM for oximetry, nitroxyl radicals used for redox imaging need to participate in redox reactions.

To optimize the adaptability of nitroxyl radicals as probes, adequate modifications need to be made. Such chemically modified nitroxyl radicals are preferentially distributed in intracellular, extracellular, and cell membrane (109). A set of redox-responsive probes to simultaneously assess redox reactions in intra- and extracellular regions were reported by Utsumi et al. (125). With the design of ${ }^{14} \mathrm{~N}$ - and ${ }^{15} \mathrm{~N}$-labeled nitroxyls, it was possible to distinguish between intra- and extracellular redox processes as demonstrated in a phantom object.

The feasibility of redox imaging using nitroxyl radicals was validated by in vitro experiments (Fig. 11), showing the time-dependent redox reaction of both membrane-permeable ${ }^{14} \mathrm{~N} /{ }^{15} \mathrm{~N}$-3-methoxycarbonyl-2,2,5,5-tetramethyl-pyrrolidine1-yloxy (MC-PROXYL) and membrane-impermeable ${ }^{14} \mathrm{~N} /{ }^{15} \mathrm{~N}$ carboxy-PROXYL. Images were acquired separately by changing the external magnetic field for EPR irradiation between ${ }^{14} \mathrm{~N}$ and ${ }^{15} \mathrm{~N}$ nuclei in FC-PEDRI (125). Figure $11 \mathrm{~A}$ is a schematic of seven phantom tubes comprising six outer tubes with liposomes encapsulated with $100 \mathrm{~m} M$ ascorbic acid: Two containing the ${ }^{15} \mathrm{~N}$ compounds are shown with red, two containing the ${ }^{14} \mathrm{~N}$ compounds are shown with blue, and two containing both compounds are shown by the red and blue stripes. There was also one central tube, containing both compounds and no liposomes. Carboxy-PROXYL does not penetrate the liposome membrane, whereas MC-PROXYL can permeate freely across the membrane and undergo 1electron reduction to the corresponding hydroxylamine. Three such PEDRI images taken at 2.9, 13.9, and $24.9 \mathrm{~min}$ are shown in Figure 11B. The image data showed that the intensity from the tubes containing MC-PROXYL in the presence of ascorbic acid-encapsulating liposomes gradually decreased with time, whereas the image intensities from tubes containing carboxy-PROXYL were constant. The rate of intensity loss from each pixel represents the differential redox imaging (Fig. 11C). It should be noted that the rate of intensity loss in the tube containing both MC- and carboxyPROXYL (indicated with stripes in Fig. 11A) was the same 
A

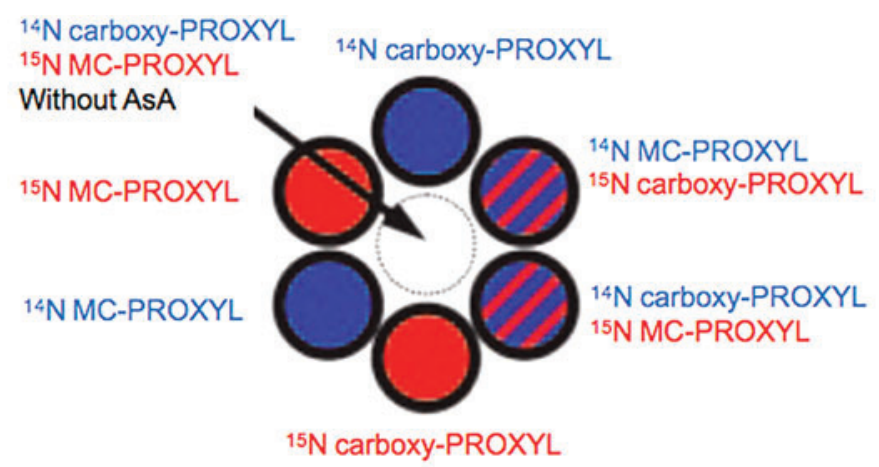

B
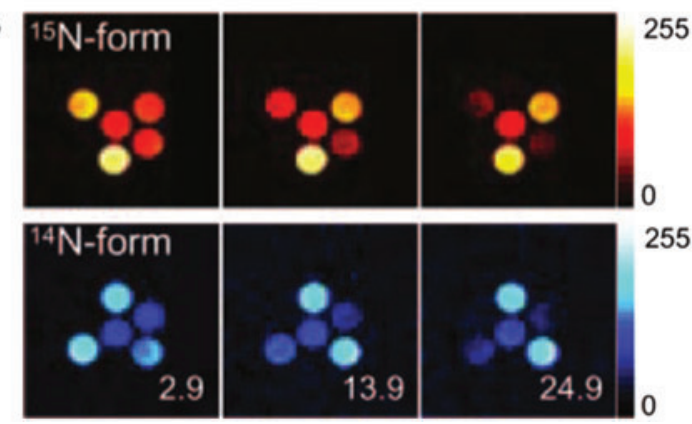

255

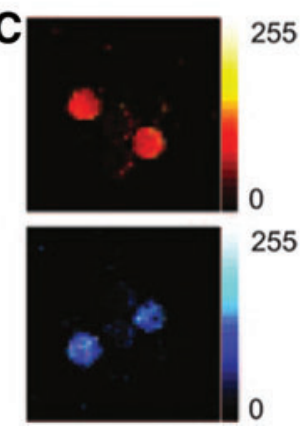

FIG. 11. Simultaneous and time-dependent PEDRI of ${ }^{15} \mathrm{~N} /{ }^{14} \mathrm{~N}$-carboxy- PROXYL and ${ }^{15} \mathrm{~N} /{ }^{14} \mathrm{~N}$-MC-PROXYL in liposomes encapsulating ascorbic acid $(100 \mathrm{~m} M)$. (A) Seven phantom tubes containing ${ }^{14} \mathrm{~N}$-labeled and/or ${ }^{15} \mathrm{~N}$-labeled nitroxyl radicals in the presence and the absence of liposomes were placed in the PEDRI so that images of ${ }^{15} \mathrm{~N}$ - and ${ }^{14} \mathrm{~N}$ enhanced images (red and blue, respectively) in (B) were obtained simultaneously at the times shown in the figures. (B) The presence of ${ }^{15} \mathrm{~N}$-carboxy-PROXYL and ${ }^{15} \mathrm{~N}$-MC-PROXYL are clearly shown by the red color, and ${ }^{14} \mathrm{~N}$-carboxy-PROXYL and ${ }^{14} \mathrm{~N}$-MC-PROXYL are indicated by the blue color. (C) The images of the decay rates for ${ }^{14} \mathrm{~N}$ - and ${ }^{15} \mathrm{~N}$-enhanced PEDRI images were calculated by assuming first-order kinetics for the time-dependent decrease of the contrast (B). Only MC-PROXYL showed decay images in both ${ }^{14} \mathrm{~N}$ - and ${ }^{15} \mathrm{~N}$-enhanced PEDRI (FOV, $48 \times 48 \mathrm{~mm}$; matrix, 64 $\times 64$; slice thickness, $10 \mathrm{~mm}$; TR/TE/T ${ }^{\mathrm{ESR}}, 1200 /$ 25/600 ms). Reprinted with permission from Utsumi et al. (125). MC-PROXYL, 3-MethoxyCarbonyl-2,2,5,5-Tetramethylpyrrolidine-1-yloxy. To see this illustration in color, the reader is referred to the web version of this article at www.liebertpub.com/ars

as that in the tube containing either MC- or carboxyPROXYL. Results from these phantom studies suggested that if two nitroxyl radicals with different isotopic substitution and different ring substituents (which direct them to different subcellular regions) lose or gain their paramagnetism, then their oxidation and reduction can be spatially resolved and distinguished. The time-dependent signal loss of the PEDRI images was observed when the nitroxyl radicals, which can permeate the liposomal bilayer, underwent reduction; whereas the nitroxyl agent incapable of crossing the membrane bilayer remained intact, and signal loss of the PEDRI images was not observed. This capability demonstrated that PEDRI combined with dual-labeled nitroxyl spin probes enabled visualization of events occurring at a nanometer scale, regardless of the intrinsic image resolution of $0.1 \mathrm{~mm}$. This capability further exploited the fact that nitroxyl radicals are efficient antioxidants that also provide protection against oxidative stress in several modalities.

Based on the results from in vitro experiments, in vivo redox imaging using PEDRI was also successfully achieved. Figure 12 shows in vivo redox imaging demonstrated in a bupivacaine (BPVC)-induced local inflammation model in mouse legs (36). BPVC is a clinically used local anesthetic agent. However, it is known to destroy skeletal muscle fibers and cause severe inflammation when injected $(7,77,106)$. Within several hours of BPVC-induced muscle transient fiber destruction, inflammatory cells locally infiltrate into treated tissues; the muscle cell itself regenerates within several weeks. Because of this effect, BPVC treatment has been used to create an animal model of muscle inflammation and regeneration. To noninvasively monitor redox status of the muscle, in vivo PEDRI was performed at 4 and $24 \mathrm{~h}$ after BPVC treatment in living mice. Two nitroxyl radicals, the cell membrane penetrable (carbamoyl- PROXYL: Fig. 12A) and the cell impermeable (carboxy-PROXYL: Fig. 12B), were used in the in vivo PEDRI experiments to confirm whether the redox reaction mainly occurs in the intracellular or extracellular compartment. Nitroxyl radical solution was carefully injected to the same region of the mouse leg that had received BPVC pretreatment. After an injection of carbamoyl-PROXYL, image intensities of both control and BPVC-treated legs (at 4 or $24 \mathrm{~h}$ ) were clearly enhanced, and this intensity decreased over time. Although the image intensities of both legs were similarly decreased at $4 \mathrm{~h}$ after BPVC treatment, the image intensity of the BPVC-treated leg at $24 \mathrm{~h}$ showed faster decay than that of the untreated leg. The redox maps clearly illustrated differences in decay rates and distributions between control and BPVC-treated legs. The average decay rate observed in the BPVC-treated legs of eight mice significantly increased at $24 \mathrm{~h}$ but not at $4 \mathrm{~h}$. Differences in decay rates of BPVC-treated and contralateral (nontreated) legs in individual mice were also calculated 
A

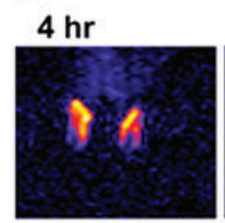

$2 \min$

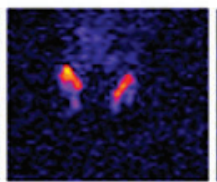

$7 \mathrm{~min}$

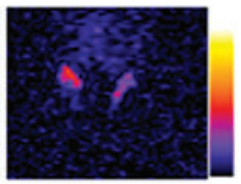

$13 \mathrm{~min}$
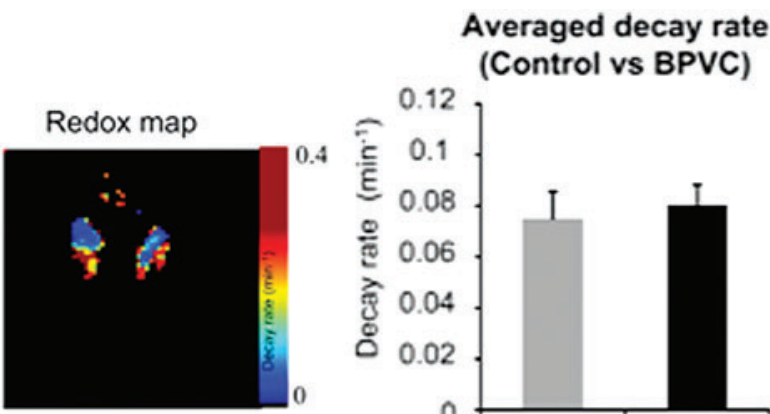

$24 \mathrm{hr}$

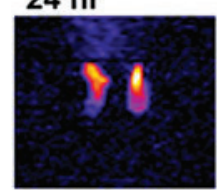

$2 \min$

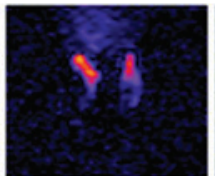

$7 \mathrm{~min}$

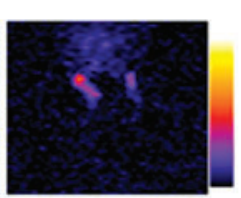

$13 \mathrm{~min}$
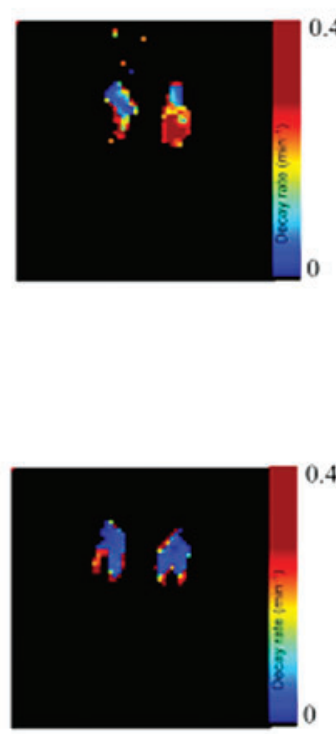
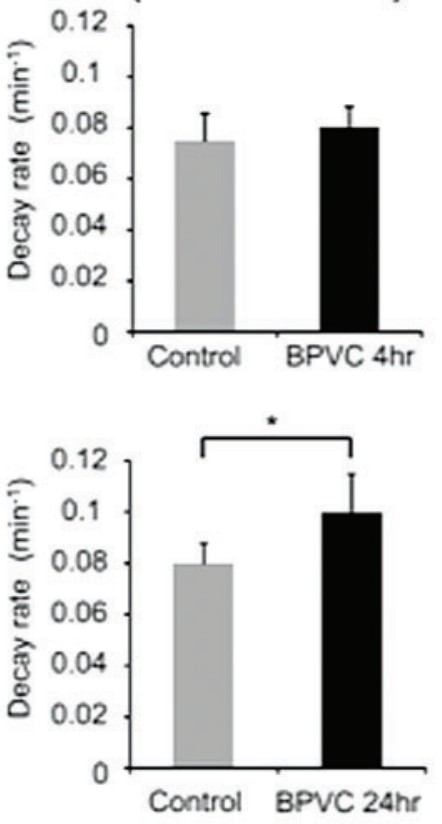

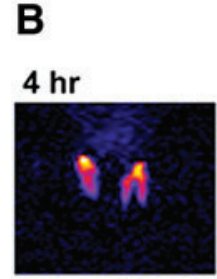

$2 \min$

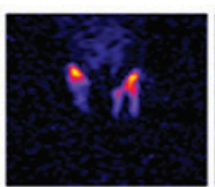

$7 \min$

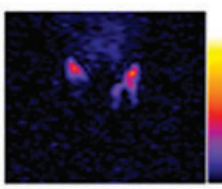

$13 \mathrm{~min}$

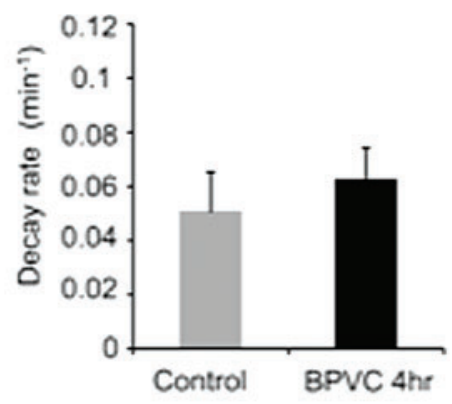

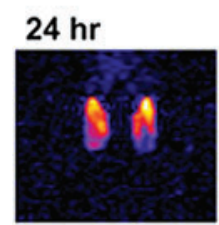

$2 \min$

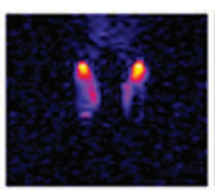

$7 \min$

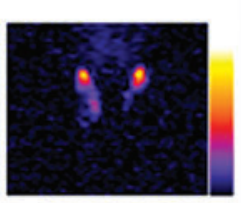

$13 \mathrm{~min}$
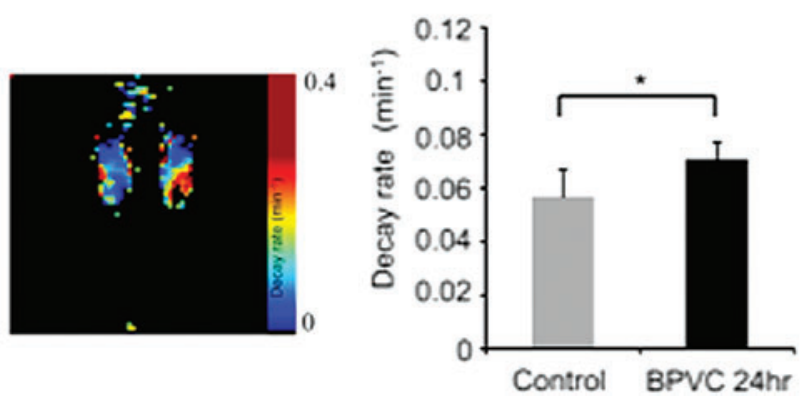

FIG. 12. Redox imaging of muscle in BPVC-treated mice by using in vivo DNP-MRI. (A) In vivo DNP-MRI images and redox maps at 4 and $24 \mathrm{~h}$ after BPVC treatment in mice. Images were taken after injection of $2.5 \mathrm{~m} M$ carbamoylPROXYL $(50 \mu \mathrm{L})$ into both legs. Redox maps were calculated by using four pharmacokinetic in vivo DNP-MRI images. Decay rates were calculated for the DNP-MRI images of untreated and BPVC-treated legs. Plots showing differences between decay rates in BPVC-treated versus untreated (contralateral) legs in individual mice. (B) In vivo DNP-MRI images and redox map at 4 and $24 \mathrm{~h}$ after BPVC treatment in mice. Images were taken after injection of $2.5 \mathrm{~m} M$ carboxy-PROXYL $(50 \mu \mathrm{L})$ into both legs $\left(N=8\right.$ per group). ${ }^{*} p<0.01$ (Other parameters are plotted as for carbamoyl-PROXYL.). Reprinted with permission from Eto et al. (36). BPVC, bupivacaine; DNP, dynamic nuclear polarization. To see this illustration in color, the reader is referred to the web version of this article at www.liebertpub.com/ars

(Fig. 12A, B, right panels). In these panels, a symbol above the line marked "even" indicates that the decay rate of the BPVC-treated leg was faster than that of the control leg.

It has been reported that probes that have multiple hyperfine lines can have efficient Overhauser enhancement. When the MRI signal enhancement by saturating electron of such probes is enough to visualize in vivo free radicals, several endogenous antioxidants can be used as redox-responsive PEDRI probes. In contrast to administering the redoxsensitive nitroxyl probe and observing the loss of signal, the 
attempt to visualize and identify various endogenous free radical intermediates derived from redox transformations was tested $(56,123)$.

Figure 13 shows the EPR signals of the intermediate of various candidate probes (56). The enhancements due to FADH and FMNH were similar to that induced by carbamoylPROXYL (enhancement factor $=3.8,4.3$, and 3.3, respectively), even though the EPR absorption spectra of both FMNH and FADH exhibit a 13-fold broader line width, compared with the spectrum of carbamoyl-PROXYL, and the ratios of enhancement factor to peak height of both FMNH and FADH were four to seven times higher than that of carbamoylPROXYL. The line widths varied from 4.2 MHz (carbamoylPROXYL) to $58.5 \mathrm{MHz}$ (FMN), which were much larger than the MRI resonance frequency. EPR excitation for PEDRI was carried out under continuous-wave irradiation, and the fluctuation of EPR irradiation was estimated within 1 ppm (corresponding to $0.5 \mathrm{kHz}$ ), which probes only a small proportion of the free radical molecules. This allows the electron transitions to be saturated much less completely in FMNH and FADH solutions than in carbamoyl-PROXYL solution. The coenzyme Q10 $\left(\mathrm{CoQ}_{10}\right) \mathrm{H}$ and radicals of vitamins $\mathrm{E}$ and $\mathrm{K}$ all enhanced the proton signals of the nonaqueous solvent: acetone for $\mathrm{CoQ}_{10} \mathrm{H}$, hexane for the vitamin $\mathrm{E}$ radical, and $\mathrm{CHCl}_{3} /$ $\mathrm{EtOH}$ for the vitamin $\mathrm{K}$ radical. Compared with carbamoyl-
PROXYL, the ratio of enhancement factor to peak height was 38 times higher for the vitamin $\mathrm{K}_{1}$ radical, 5 times higher for the vitamin $\mathrm{E}$ radical, and 2 times higher for $\mathrm{CoQ}_{10} \mathrm{H}$. Also, the electrons of these probes can be separately saturated and induce DNP by adjusting the EPR irradiation frequency. The result indicates that it is possible to simultaneously visualize various free radical intermediates of endogenous redox molecules (56).

\section{pH Mapping with PEDRI}

Aberration of normal tissue $\mathrm{pH}$ homeostasis in the human body has been reported for a number of pathological conditions that include cancers $(123,135)$, myocardial (98) and brain ischemia $(73,132)$, and chronic pulmonary $(60)$ and kidney diseases (74). The extracellular tumor tissue acidosis, $\mathrm{pH}_{\mathrm{e}}$, has been identified as a significant factor in cancer pathophysiology contributing to tumor initiation, progression, and therapy (43). Therefore, in vivo $\mathrm{pH}_{\mathrm{e}}$ imaging of the tumor tissue microenvironment (TME) may provide an invaluable tool for diagnosis, understanding of disease progression, and treatment optimization. Recently developed variable field (VF) (69) and variable radio frequency (VRF) PEDRI (33) approaches allow for functional mapping using nitroxide or trityl probes while additionally keeping the capability to provide anatomical images. VF (69) and VRF
FIG. 13. Typical EPR spectra (A), the absorption EPR spectra (B), and simultaneous DNP-MRI image (C) of free radical intermediates from FMN, FAD, $\mathrm{CoQ}_{10}$, vitamin E, vitamin $K_{1}$, and the synthetic stable radical $14 \mathrm{~N}$ carbamoyl-PROXYL. The vertical solid line in part $\mathrm{b}$ indicates the frequency of EPR irradiation for PEDRI $(527.5 \mathrm{MHz})$, which is the resonance frequency of the central peak of carbamoylPROXYL. MRI spectra with and without EPR irradiation were obtained with a spin echo sequence at $850 \mathrm{kHz}$ by using a homemade in vivo PEDRI system kept at room temperature. Reprinted and adapted with permission from Hyodo et al. (56). (c) 2014 American Chemical Society. FMN, flavin mononucleotide; $\mathrm{FAD}$, flavin adenine dinucleotide. To see this illustration in color, the reader is referred to the web version of this article at www.liebertpub .com/ars
A

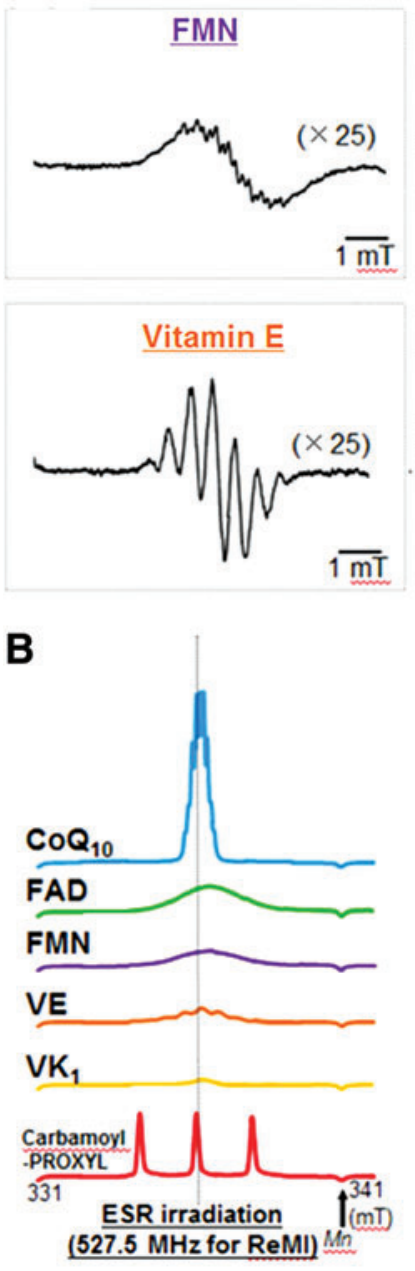

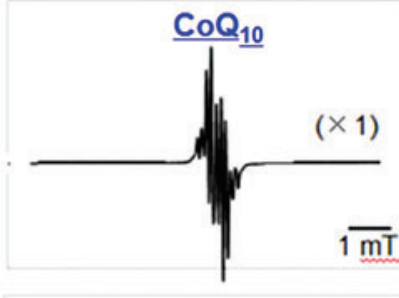

${ }^{14} \mathrm{~N}$-carbamoyl-PROXYL
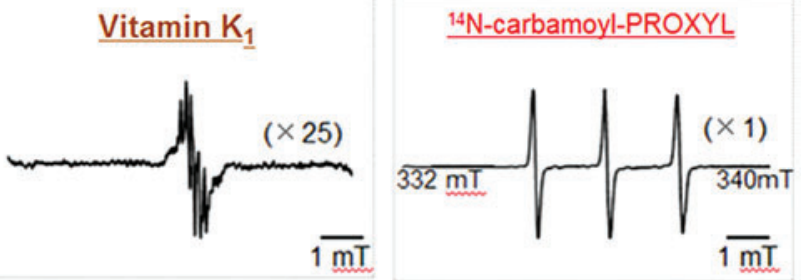

C
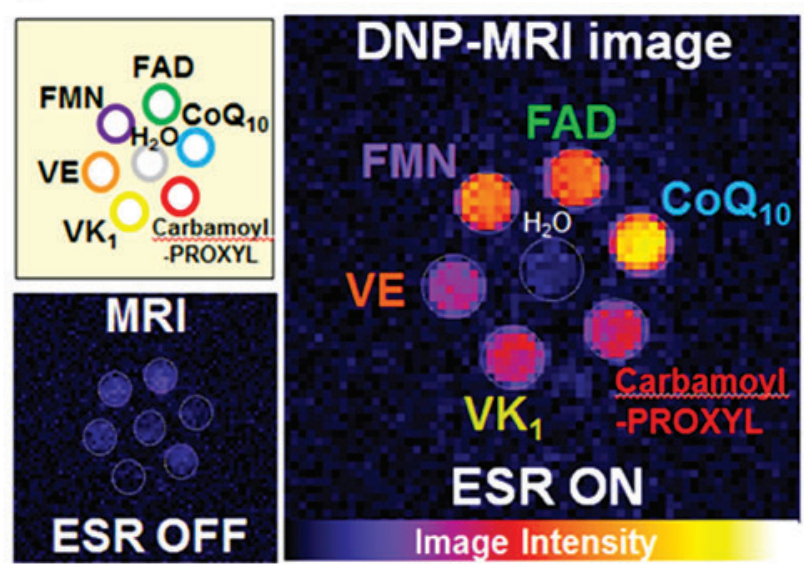


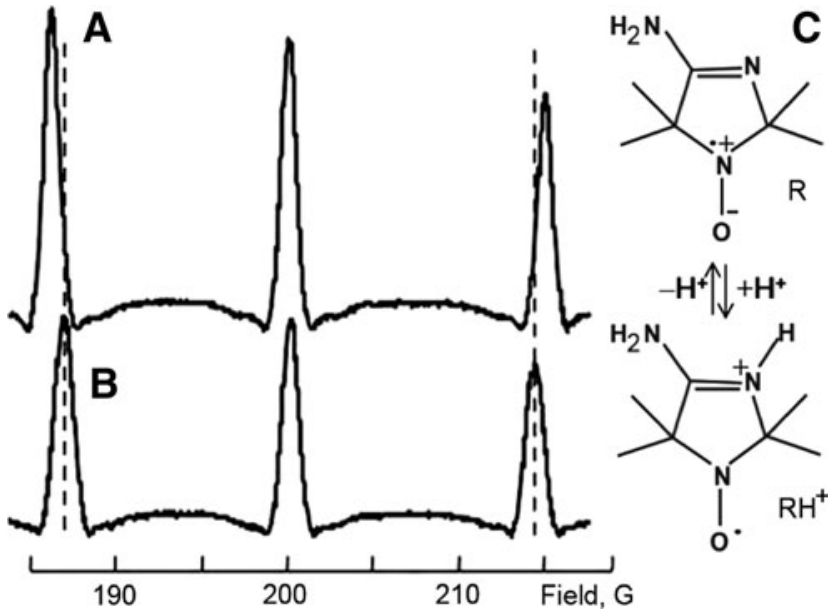

FIG. 14. FC-DNP spectra of the nitroxide NR1 obtained in phosphate-citrate buffer $(10 \mathrm{mM}$ each) at $\mathrm{pH}$ 7.62 (A) and pH 4.98 (B), and the scheme of the reversible protonation of the NR1 radical, $\mathrm{p} K_{\mathrm{a}}=6.1(\mathrm{C})$. Frequency of EPR irradiation $563.2 \mathrm{MHz}$, irradiation time, $500 \mathrm{~ms}$, repetition time, $1140 \mathrm{~ms}$; step size $=0.04 \mathrm{G} ; P=0.8 \mathrm{~W}$, sample volume, $5 \mathrm{~mL}$. The preferable resonance structures of protonated, $\mathrm{RH}^{+}$, and unprotonated, $\mathrm{R}$, forms are shown illustrating higher unpaired electron density on nitrogen atom $\mathrm{N}-1$ in the unprotonated form. Protonation results in a DNPdetected difference in hyperfine splitting $\left(\Delta \mathrm{a}_{\mathrm{N}}=0.8 \mathrm{G}\right)$ between $\mathrm{R}$ and $\mathrm{RH}^{+}$forms. A dotted line is extended from low- and high-field peaks of the spectra (B) to aid the eye. Reprinted with permission from Khramtsov et al. (69).

PEDRI (33) approaches allow for mapping the chemical microenvironment by using probes with functionally dependent ratiometric spectral parameters. The valuable spectral parameters at each pixel can be extracted from a limited number of PEDRI acquisitions acquired at preselected EPR excitation fields or EPR excitation frequencies. This allows for functional mapping using specifically designed paramagnetic probes, together with high-quality spatial resolution and short acquisition time. The concept was first verified by using VF PEDRI and a $\mathrm{pH}$-sensitive nitroxide probe (69).

Figure 14 shows typical DNP spectra of the nitroxide NR1 acquired in acid, $\mathrm{pH} 4.98$, and slightly alkaline, $\mathrm{pH} 7.62$, aqueous solutions corresponding to dominant contributions of the protonated, $\mathrm{RH}^{+}$, and nonprotonated, $\mathrm{R}$, forms of the radical, correspondingly, $\mathrm{p} K_{\mathrm{a}}=6.1$ (70). The significantly larger distance between the outer lines of the triplet spectra observed for the alkaline solution of the nitroxide is in agreement with previously reported larger nitrogen hyperfine splitting (hfs) for the R form (70).

The chemical equilibrium shown in Figure 14 illustrates the effect of protonation of the atom N-3 of the radical heterocycle resulting in decreasing unpaired electron density at the nitrogen nucleus of the N-O fragment, and, as a consequence, in lowered hfs for the $\mathrm{RH}^{+}$form. Note that at low EPR frequency, 563.2 MHz in Figure 14, the three lines of the spectrum are unequally spaced due to the Breit-Rabi effect $(13,102)$.

The $\mathrm{pH}$-dependent DNP spectral changes allow for preferable excitation of EPR resonances of $\mathrm{R}$ or $\mathrm{RH}^{+}$forms of the nitroxide NR1 as illustrated in Figure 15 for the phantom sample of the two tubes filled with an aqueous solution of NR1 titrated to alkaline and acidic $\mathrm{pH}$ values. The stepped variation of the EPR irradiation field, $B^{E P R}$, resulted in the subsequent changes in image intensity with the maximal image intensities of alkaline (predominantly $\mathrm{R}$ form) and acidic (predominantly $\mathrm{RH}^{+}$form) solutions when $B^{E P R}$ is equal to $83.2 \mathrm{G}$ and $84 \mathrm{G}$, respectively. Note that the observed $0.8 \mathrm{G}$ difference in $B^{E P R}$ values between the brightest images of $\mathrm{R}$ and $\mathrm{RH}^{+}$forms is in excellent agreement with the maximal pH-dependent change of hfs shown in Figure 14.

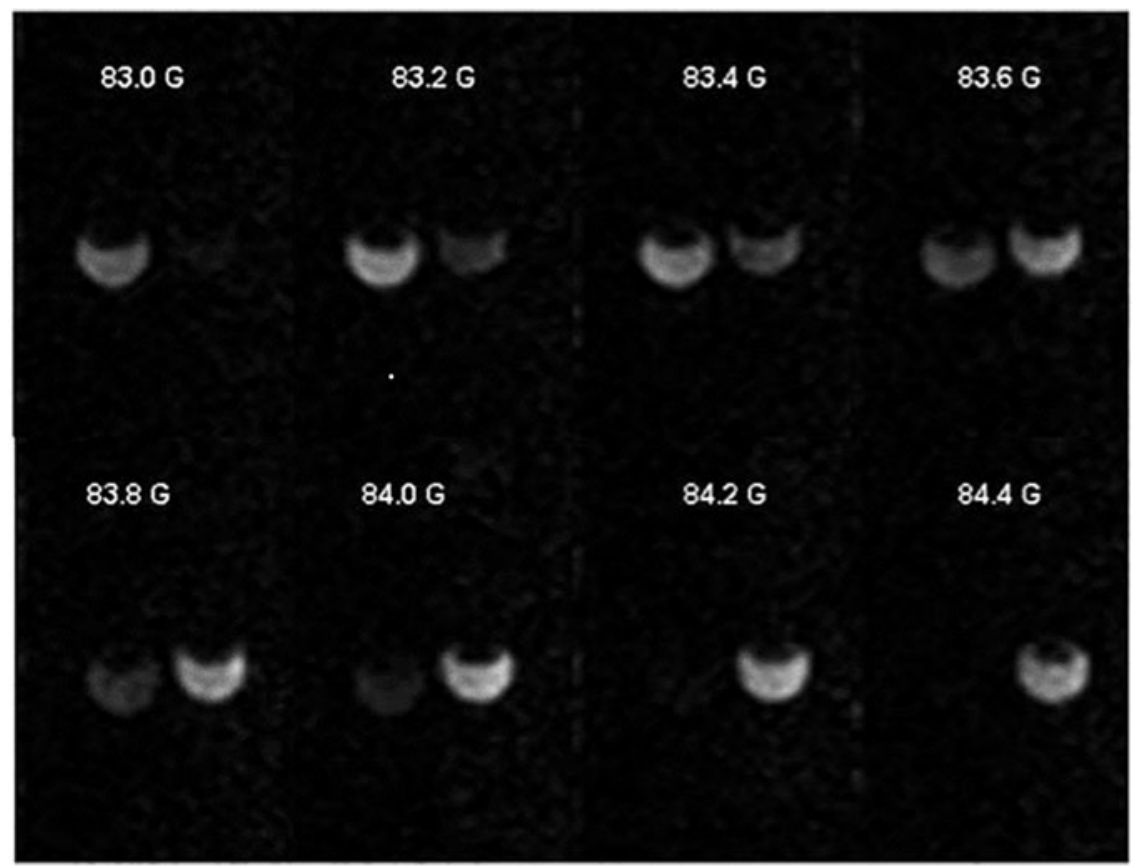

FIG. 15. Sequence of PEDRI images of the phantom sample of a pair of tubes, $10 \mathrm{~mm}$ diameter, containing $1 \mathrm{~m} M$ aqueous solutions of the NR1 probe at $\mathrm{pH} 9$ (left tube) and pH 2 (right tube). Images were acquired at EPR frequency $282 \mathrm{MHz}$ $(100 \mathrm{G}$ for the EPR center field) with evolution field stepped in the range from $83.0 \mathrm{G}$ to $84.4 \mathrm{G}$ around the position of the low-field EPR component of the NR1 triplet spectrum. The observed variation of the image intensity with the shift in EPR irradiation field, $B^{E P R}$, illustrates the subsequent changes with the maximal image intensity of $\mathrm{R}$ form (left tube) and $\mathrm{RH}^{+}$form (right tube) when $B^{E P R}$ is equal to $83.2 \mathrm{G}$ and $84 \mathrm{G}$, respectively. Reprinted with permission from Khramtsov et al. (69). 


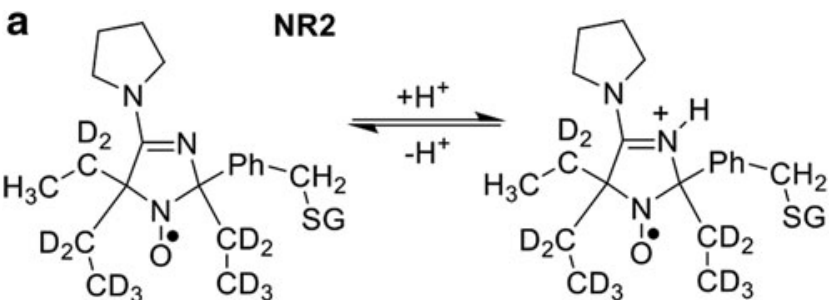

SG stands for glutathione residue

b

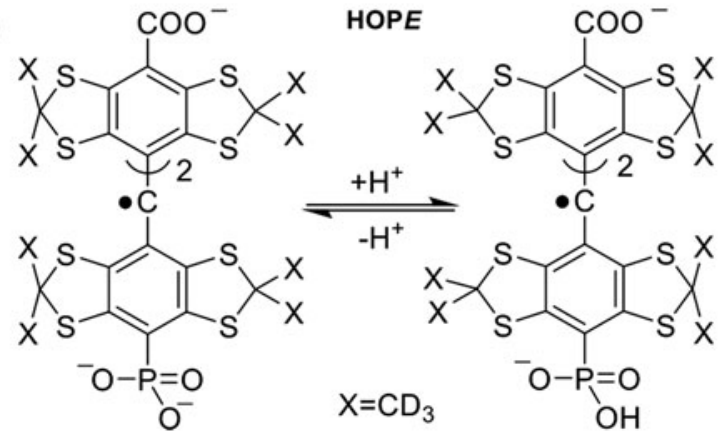

FIG. 16. (a, b) The chemical structures and proton exchange equilibrium for $\mathrm{pH}$-sensitive nitroxide, NR2, and trityl, HOPE, probes. HOPE, trityl probe with spectral sensitivity to $\mathrm{pH}, p \mathrm{O}_{2}$, and $\mathrm{Pi}$ in extracellular tissue microenvironment.
Based on the data shown in Figure 15, EPR excitation at the field values that coincide with DNP spectral peak positions of $\mathrm{RH}^{+}$and $\mathrm{R}$ forms of the probe will generate two PEDRI images with signal intensities that are proportional to the concentrations of the corresponding ionization states of the probe. Taking into account that the ratio of concentrations of protonated and nonprotonated forms of the probe is directly related to $\mathrm{pH}\left(\left[\mathrm{RH}^{+}\right] / \mathrm{R}\right)=\left(\left[\mathrm{H}^{+}\right] / \mathrm{K}_{\mathrm{a}}\right)$, this provides an opportunity to convert these two PEDRI images into a $\mathrm{pH}$ map.

Alternatively to VF PEDRI, the VRF PEDRI approach uses a stationary magnetic field but different EPR radio frequencies (RF). The ratio of Overhauser enhancements measured at each pixel at two different excitation frequencies corresponding to the resonances of protonated and deprotonated forms of a $\mathrm{pH}$-sensitive nitroxide is converted to a $\mathrm{pH}$ map by using a corresponding calibration curve. Elimination of FC decreased the acquisition time by exclusion of the periods of ramping and stabilization of the magnetic field. Improved magnetic field homogeneity and stability allowed for the fast MRI acquisition modalities such as fast spin echo. In total, about a 30-fold decrease in EPR irradiation time was achieved for VRF PEDRI (2.4 s) (69) compared with VF PEDRI (70 s) (33), as tested with similar aqueous solutions of the NR1 radical. This is particularly important for in vivo applications enabling one to overcome the limiting stability
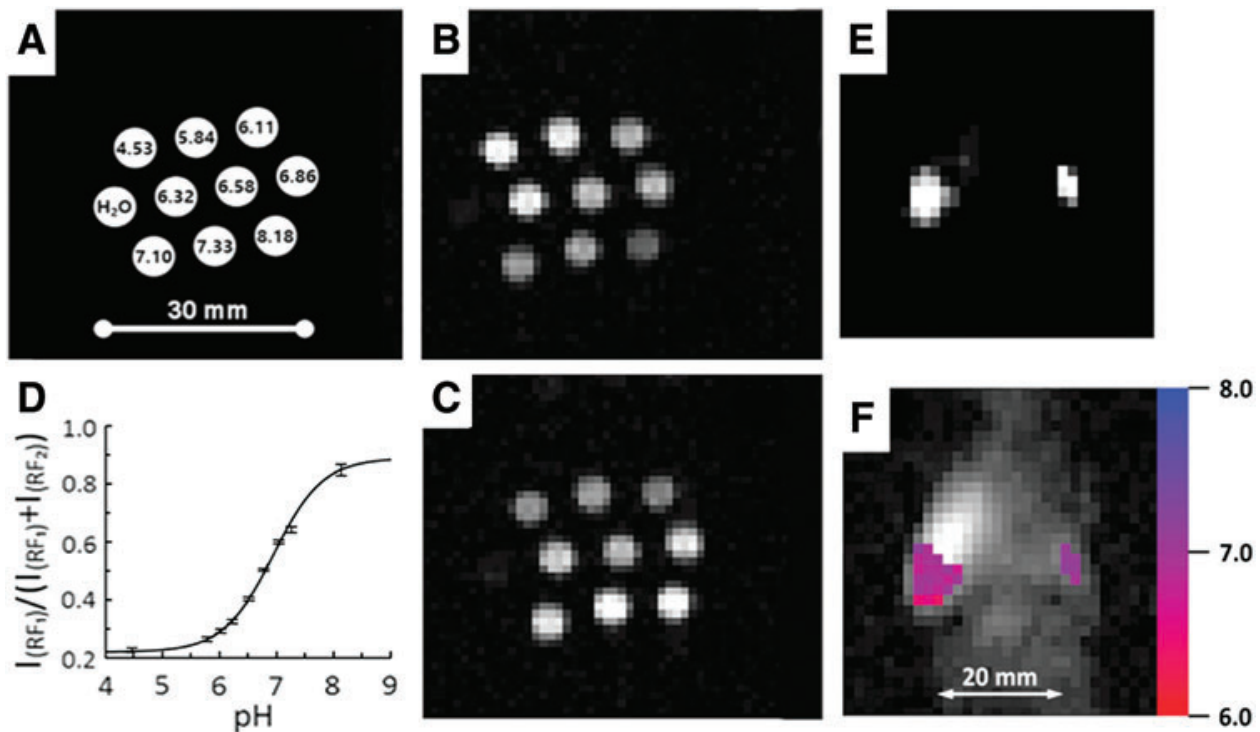

FIG. 17. VRF PEDRI pH calibration (A-D) and in vivo pH mapping (E, F) by using NR2 probe. Calibration has been performed by using a 10-tube phantom (A) at room temperature. PEDRI images were acquired at two EPR irradiations, $\mathrm{RF}_{2}=559.3 \mathrm{MHz}(\mathbf{B})$ and $\mathrm{RF}_{1}=562.1 \mathrm{MHz}(\mathbf{C})$, acquisition time, $8.4 \mathrm{~s}$. The tube with water alone is not visible on either image due to lower intensity compared with the signal from tubes containing the paramagnetic probe. EPR off image (not shown) was subtracted from both $\mathrm{EPR}$ on images acquired at $\mathrm{RF}_{1}$ and $\mathrm{RF}_{2}$, yielding image intensities, $\mathrm{I}\left(\mathrm{RF} \mathrm{F}_{1}\right)$ and $\mathrm{I}\left(\mathrm{RF} \mathrm{F}_{2}\right)$. (D) $\mathrm{pH}$ dependence of the ratio $\mathrm{I}\left(\mathrm{RF}_{1}\right) /\left(\mathrm{I}\left(\mathrm{RF}_{1}\right)+\mathrm{I}\left(\mathrm{RF}_{2}\right)\right)$. Solid line is nonlinear least-squares fit of the data to a conventional titration equation, yielding $\mathrm{pK}_{\mathrm{a}}$ value equal to $6.75 \pm 0.05$. Error bars represent the standard deviation. In vivo PEDRI $\mathrm{pH}$ mapping was performed in the anesthetized breast tumor-bearing mouse (E, F). Paramagnetic NR2 probe was injected into the tumor (number 4 mammary gland, left) and normal mammary gland (number 9, right). (E) Qualitative visualization of the distribution of the NR2 probe, in vivo. The image is the average of two PEDRI images acquired at two EPR frequencies, $\mathrm{RF} 1=562.1 \mathrm{MHz}$ and RF2 $=559.3 \mathrm{MHz}, \mathrm{NMR}$ frequency, $784.9 \mathrm{kHz}$, matrix, $64 \times 64$; field of view, $80 \times 80 \mathrm{~mm}$. Irradiation time was $8.4 \mathrm{~s}$ for each acquisition. (F) $\mathrm{pH}$ map (in color) calculated from two PEDRI images superimposed with the MRI image (gray scale) showing the coronal view of the mouse. Reprinted and adapted with permission from Samouilov et al. (108). (C) 2014 American Chemical Society. VRF, variable radio frequency. To see this illustration in color, the reader is referred to the web version of this article at www.liebertpub.com/ars 
of paramagnetic probes and sample overheating by reducing RF power deposition.

To perform PEDRI $\mathrm{pH}_{\mathrm{e}}$ mapping of TME, there is a need for paramagnetic $\mathrm{pH}$ probes that meet the following requirements: (i) appropriate $\mathrm{pK}_{\mathrm{a}}$ values in the range from 6.1 to 6.9 that allow $\mathrm{pH}$ measurements of slightly acidic TME $\mathrm{pH}$ values; (ii) comparatively narrow linewidth to obtain a high enhancement and decreased RF power deposition; (iii) sufficient stability of paramagnetic fragments in a highly reducing tumor microenvironment; and (iv) a hydrophilic structure that ensures extracellular probe localization. The nitroxide NR1 used to prove the concept of VF and VRF PEDRI $(33,69)$ has a very short life-time in vivo due to its fast reduction to the corresponding hydroxylamine and its applications in vivo are hardly possible.

The nitroxide NR2 represents the structure (Fig. 16a) of a paramagnetic $\mathrm{pH}$ probe carefully designed for in vivo monitoring of $\mathrm{pH}_{\mathrm{e}}$ in TME. The $\mathrm{pK}_{\mathrm{a}}$ value of the probe has been tuned by a variation of substitute at position 4 of the radical heterocycle, resulting in an optimal range of $\mathrm{pH}$ sensitivity centered at slightly acidic $\mathrm{pH}_{\mathrm{e}}$ of TME $\left(\mathrm{pK}_{\mathrm{a}}=6.6\right.$ at $\left.37^{\circ} \mathrm{C}\right)$. Partial deuteration of the NR2 resulted in the narrowing EPR line (1.2 G for NR2 vs. $2.1 \mathrm{G}$ for undeuterated analog) required for efficient saturation by RF irradiation, which is of critical importance for obtaining higher PEDRI enhancement and allowing for a shorter acquisition time. The bulky ethyl substitutes at positions 2 and 5 of the radical heterocycle of the NR2 serve to protect the paramagnetic NO fragment against bioreduction, significantly enhancing its biostability. Extracellular localization of the probe has been achieved by binding the nitroxide label to hydrophilic tripeptide, glutathione, preventing the resulting NR2 probe from diffusion across the hydrophobic lipid bilayer of the biomembranes and, therefore, enforcing probe localization in extracellular aqueous volumes (108).

Figure 17A-D shows the $\mathrm{pH}$ calibration of the NR2 probe using VRF PEDRI obtained for a 10-tube phantom (Fig. 17a) containing the NR2 solutions of different $\mathrm{pH}$ values. EPR frequencies were preselected to correspond to the maximal $\mathrm{NMR}$ intensities of $\mathrm{R}$ and $\mathrm{RH}^{+}$forms. A fast spin echo sequence has been applied with an acquisition time of $8.4 \mathrm{~s}$ for each image (Fig. 17B, C). The EPR off image was subtracted from both EPR on images acquired at $\mathrm{RF}_{1}$ and $\mathrm{RF}_{2}$, yielding image intensities, $\mathrm{I}\left(\mathrm{RF}_{1}\right)$ and $\mathrm{I}\left(\mathrm{RF}_{2}\right)$, respectively. The $\mathrm{pH}$ dependence of intensities ratio $\mathrm{I}\left(\mathrm{RF}_{1}\right) /$ $\left(\mathrm{I}\left(\mathrm{RF}_{1}\right)+\mathrm{I}\left(\mathrm{RF}_{2}\right)\right)$ shown in Figure $17 \mathrm{D}$ is described by the titration curve with the observed $\mathrm{pK}_{\mathrm{a}}$ value of $\mathrm{NR} 2$ probe
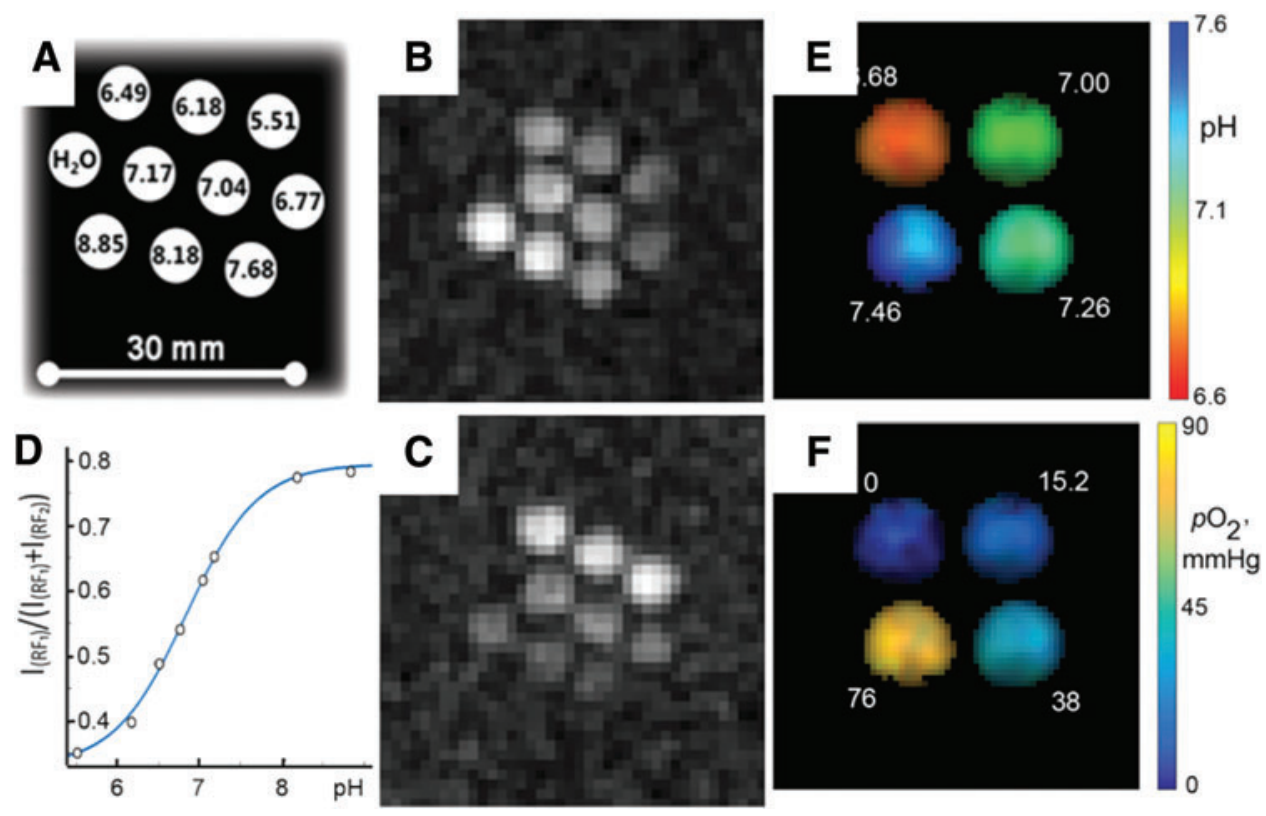

FIG. 18. VRF PEDRI pH calibration (A-D) and dual function $\mathrm{pH}$ and $p \mathrm{O}_{2}$ mapping (E, F) by using trityl $\mathrm{HOPE}$ probe. The phantom used for $\mathrm{pH}$ calibration consists of 9 sealed glass tubes filled with $1 \mathrm{~mL}$ of degassed $0.5 \mathrm{~m} M$ probe solutions, $150 \mathrm{~m} M$ sodium chloride, at different $\mathrm{pH}$ values indicated in the (A), and one reference tube filled with degassed solution of sodium chloride only. Images were acquired by using RF1 $=573.625 \mathrm{MHz}(\mathbf{B})$ and $\mathrm{RF} 2=573.95 \mathrm{MHz}(\mathbf{C}) \mathrm{EPR}$ irradiation frequencies, respectively; NMR frequency, $856 \mathrm{kHz}$, irradiation time, $130 \mathrm{~s}$; matrix, 64×64; field of view, $80 \times 80 \mathrm{~mm}$. (D) $\mathrm{pH}$ dependence of the ratio $\mathrm{I}(\mathrm{RF} 1) /(\mathrm{I}(\mathrm{RF} 1)+\mathrm{I}(\mathrm{RF} 2))$. Solid line is nonlinear least-squares fit of the data to a conventional titration equation, yielding $\mathrm{pK}_{\mathrm{a}}$ value equal to $6.9 \pm 0.03$. (E, F) PEDRI mapping of $\mathrm{pH}$ and $p \mathrm{O}_{2}$ of a phantom sample. The sample consisted of four tubes filled with $1 \mathrm{~m} M$ solution of HOPE probe of different oxygen concentrations and $\mathrm{pH}$ values (indicated in Fig. 18E, F, respectively). PEDRI images were acquired at two frequencies of EPR radiation, 456.6 MHz and $457 \mathrm{MHz}$, and at two power values, $0.5 \mathrm{~W}$ and $4.0 \mathrm{~W}$. The calculated $\mathrm{pH}$ values are 6.72 $\pm 0.05,7.04 \pm 0.05$, $7.27 \pm 0.05$, and 7.45 \pm 0.07 , and $\mathrm{pO}_{2}$ values are $5 \pm 3,14 \pm 3,35 \pm 4$, and $81 \pm 6 \mathrm{mmHg}$. MRI data were acquired by fast spin echo method, matrix size, $64 \times 64$; field of view, $40 \times 40 \mathrm{~mm}$, NMR frequency, $686.3 \mathrm{kHz}$; total acquisition time, $4.2 \mathrm{~min}$. (A-D) Reprinted with permission from Takashi et al. (122). (E, F) are provided through the courtesy of Artem Gorodetskii, IMMR center, WVU. To see this illustration in color, the reader is referred to the web version of this article at www. liebertpub.com/ars 
equal to $6.75 \pm 0.05$ in agreement with the EPR-measured $\mathrm{pK}_{\mathrm{a}}$ value, $6.74 \pm 0.05$ (108).

Figure 17E, F demonstrates the application of VRF PEDRI for $\mathrm{pH}_{\mathrm{e}}$ mapping of living tissue in the tumor-bearing mouse by using the NR2 radical. Two PEDRI images are acquired during $8.4 \mathrm{~s}$ EPR irradiation at two preselected EPR frequencies, which correspond to EPR resonances of $\mathrm{RH}^{+}$and $\mathrm{R}$ forms of deuterated NR2 probe. The ratio of the signal intensities of these two images corresponds to the $\left[\mathrm{RH}^{+}\right] /[\mathrm{R}]$ ratio, therefore allowing the conversion of two PEDRI images into a $\mathrm{pH}$ map by using the calibration curve shown in Figure 17D. The probe distribution area in tumor (Fig. 17E left) is about $1 \mathrm{~cm}^{2}$, which is close to the value of the tumor cross-sectional area (the measured tumor size is about $1.2 \times 0.9 \mathrm{~cm})$, therefore supporting probe localization within the tumor. The probe distribution area in the mammary gland (Fig. 17E right) is less than $0.2 \mathrm{~cm}^{2}$, being close to its size. Figure 17F shows a $\mathrm{pH}$ map (in color) superimposed with low-field MRI (gray scale) representing the coronal view of the mouse. The broader $\mathrm{pH}_{\mathrm{e}}$ distribution in tumor in the range from 6.4 to 7.1 compared with $\mathrm{pH}_{\mathrm{e}}$ distribution in the mammary gland from $\mathrm{pH} 7.0$ to 7.2 was observed in agreement with high heterogeneity of the tumor microenvironment. Average values of $\mathrm{pH}_{\mathrm{e}}$ in tumor and mammary gland were found to be $6.8 \pm 0.1$ and $7.1 \pm 0.1$, respectively, supporting significant tumor tissue acidosis. Note that a sufficiently slow reduction of the NR2 even in highly reducing tumor tissue (half-life of about $5 \mathrm{~min}$ ) allowed for quantitative assessment of spatially resolved information on tissuereducing capacity in complement to $\mathrm{pH}$ measurements (12) by mapping decay of the PEDRI signal at each pixel. Therefore, the same $\mathrm{pH}$ probe can be used for simultaneous mapping of $\mathrm{pH}$ and redox status.

Trityl radicals have advantages over nitroxides for in vivo PEDRI applications due to their extraordinary high stability in living tissues and long relaxation times, allowing for a maximum saturation with limited RF power deposition. These compounds were first developed for biomedical applications by Nycomed Innovation (119) and have been used for in vivo EPR (34) and PEDRI oximetry (75). In addition, trityl derivatives containing amino (27) or phosphono groups (26) demonstrate dual function oxygen and $\mathrm{pH}$ spectral sensitivity. Recently, trityl probe with spectral sensitivity to $\mathrm{pH}, p \mathrm{O}_{2}$, and $\mathrm{Pi}$ (inorganic phosphate) in an extracellular tissue microenvironment (termed HOP $E$ probe, see Fig. 16b) has been synthesized $(10,26)$ and used for concurrent multifunctional assessment of TME in tumor-bearing mice by using low-field EPR spectroscopy (11). In our opinion, the PEDRI approach in combination with the HOPE probe provides an opportunity for multifunctional mapping of a tissue microenvironment in living subjects.

Figure 18A-D shows VRF PEDRI pH calibration performed by using a phantom sample containing anoxic solutions of the HOPE probe at different $\mathrm{pH}$ values. Acquisitions of two PEDRI images obtained with EPR irradiations at two preselected EPR frequencies that correspond to maximal NMR intensities of $\mathrm{R}$ and $\mathrm{RH}^{+}$forms of the HOPE probe (Fig. 16) allow one to calculate the $\mathrm{pH}$ calibration curve shown in Figure 18D (cf. with Fig. 17A-D for the NR2) (122). In case of dual $\mathrm{pH}$ and oxygen mapping, the number of acquisitions has to be extended by the addition of PEDRI images acquired at different RF powers to assess oxygen concentration (75). Figure 18E, F illustrates dual-function $\mathrm{pH}$ and $p \mathrm{O}_{2}$ mapping of a phantom consisting of four tubes prepared with different $\mathrm{pH}$ and oxygen concentrations and obtained by acquisition of a total of four PEDRI images at different EPR frequencies (x2) and different RF powers (x2). The conversion of these images to $\mathrm{pH}$ (Fig. 18E) and oxygen (Fig. 18F) maps with spatial resolution of $0.6 \mathrm{~mm}$ and field of view $40 \times 40 \mathrm{~mm}^{2}$ provides functional accuracy of about 0.05 $\mathrm{pH}$ units of $\mathrm{pH}$ and 3-4 mmHg of $p \mathrm{O}_{2}$ for the physiologically relevant $\mathrm{pH}$ and oxygen ranges. The calculated mean values of $\mathrm{pH}$ and $p \mathrm{O}_{2}$ are in reasonable agreement with the experimental ones. Note that acquisition of additional PEDRI images at intermediate EPR frequency, (RF1+RF2)/2, may provide information on the spatial distribution of phosphate due to the fact that Pi facilitates proton exchange between $\mathrm{R}$ and $\mathrm{RH}^{+}$forms of the HOPE probe, therefore resulting in appearance of EPR signal intensity at the intermediate EPR frequency (see review (68) for details).

In summary, VF and VRF PEDRI techniques in combination with functional paramagnetic probes offer an opportunity for the mapping of specific parameters of a local chemical microenvironment, including measurements in vivo. Application of multifunctional radicals such as HOPE probes can further extend the capability of PEDRI for concurrent mapping of several chemical parameters of a local microenvironment.

\section{Conclusions}

PEDRI has been developed since the 1980s as a free radical imaging method based on the Overhauser effect. It has proved to be applicable to in vivo imaging by introducing optimal tracers and pulse sequences. The possibility of generating high-resolution PEDRI images with corresponding anatomical images has realized the quantitative measurement of $\mathrm{pO}_{2}$, tissue permeability, redox status, and $\mathrm{pH}$. Such functional information obtained from PEDRI has been applied to various disease models, preclinically giving insights into the pathology and etiology of human disease.

\section{Acknowledgments}

This work was partially supported by NIH grants 1ZIABC010477-14 (MKC), CA194013 (VVK), CA192064 (VVK), and U54GM104942 (VVK); by KAKENHI grant 16H05113 (H.U.) from the Japan Society for the Promotion of Science (HU); and by start-up grant from the WVCTSI (VVK).

\section{References}

1. Ahmad R and Kuppusamy P. Theory, instrumentation, and applications of electron paramagnetic resonance oximetry. Chem Rev 110: 3212-3236, 2010.

2. Al-Waili NS, Butler GJ, Beale J, Hamilton RW, Lee BY, and Lucas P. Hyperbaric oxygen and malignancies: a potential role in radiotherapy, chemotherapy, tumor surgery and phototherapy. Med Sci Monit 11: RA279RA289, 2005.

3. Andrew ER. N.m.r. Imaging of intact biological systems. Philos Trans R Soc Lond B Biol Sci 289: 471-481, 1980.

4. Ardenkjær-Larsen JH, Laursen I, Leunbach I, Ehnholm G, Wistrand L-G, Petersson JS, and Golman K. EPR and DNP properties of certain novel single electron contrast 
agents intended for oximetric imaging. J Magn Reson 133: 1-12, 1998.

5. Benial AMF, Utsumi H, Ichikawa K, Murugesan R, Yamada K, Kinoshita Y, Naganuma T, and Kato M. Dynamic nuclear polarization studies of redox-sensitive nitroxyl spin probes in liposomal solution. J Magn Reson 204: 131-138, 2010.

6. Bennett MH, Feldmeier J, Smee R, and Milross C. Hyperbaric oxygenation for tumour sensitisation to radiotherapy. Cochrane database Syst Rev 4: CD005007, 2012.

7. Benoit PW and Belt WD. Destruction and regeneration of skeletal muscle after treatment with a local anaesthetic, bupivacaine (Marcaine). J Anat 107: 547-556, 1970.

8. Berliner $\mathrm{J}$ and Fujii $\mathrm{H}$. Magnetic resonance imaging of biological specimens by electron paramagnetic resonance of nitroxide spin labels. Science (80-) 227: 517-519, 1985.

9. Berliner LJ and Fujii H. EPR imaging of diffusional processes in biologically relevant polymers. J Magn Reson 69: 68-72, 1986.

10. Bobko AA, Dhimitruka I, Zweier JL, and Khramtsov VV. Fourier transform EPR spectroscopy of trityl radicals for multifunctional assessment of chemical microenvironment. Angew Chemie Int Ed 53: 2735-2738, 2014.

11. Bobko AA, Eubank TD, Driesschaert B, Dhimitruka I, Evans J, Mohammad R, Tchekneva EE, Dikov MM, and Khramtsov VV. Interstitial inorganic phosphate as a tumor microenvironment marker for tumor progression. Sci Rep 7: 41233, 2017.

12. Bobko AA, Eubank TD, Voorhees JL, Efimova O V., Kirilyuk IA, Petryakov S, Trofimiov DG, Marsh CB, Zweier JL, Grigor'ev IA, Samouilov A, and Khramtsov $\mathrm{VV}$. In vivo monitoring of $\mathrm{pH}$, redox status, and glutathione using L-band EPR for assessment of therapeutic effectiveness in solid tumors. Magn Reson Med 67: 18271836, 2012.

13. Breit G and Rabi II. Measurement of Nuclear Spin. Phys Rev 38: 2082-2083, 1931.

14. Brizel DM, Hage WD, Dodge RK, Munley MT, Piantadosi CA, and Dewhirst MW. Hyperbaric oxygen improves tumor radiation response significantly more than carbogen/nicotinamide. Radiat Res 147: 715, 1997.

15. Brown JM and Giaccia AJ. The unique physiology of solid tumors: opportunities (and problems) for cancer therapy. Cancer Res 58: 1408-1416, 1998.

16. Buxton RB. The physics of functional magnetic resonance imaging (fMRI). Reports Prog Phys 76: 96601, 2013.

17. Cage B, McNeely JH, Russek SE, and Halpern HJ. Thermomagnetic properties of the Finland trityl radical. J Appl Phys 105: 43905, 2009.

18. Carden DL and Granger DN. Pathophysiology of ischaemia-reperfusion injury. J Pathol 190: 255-266, 2000.

19. Carreau A, Hafny-Rahbi B El, Matejuk A, Grillon C, and Kieda C. Why is the partial oxygen pressure of human tissues a crucial parameter? Small molecules and hypoxia. J Cell Mol Med 15: 1239-1253, 2011.

20. Carver TR and Slichter CP. Experimental verification of the overhauser nuclear polarization effect. Phys Rev 102: 975-980, 1956.

21. Ceelen W, Smeets P, Backes W, Van Damme N, Boterberg T, Demetter P, Bouckenooghe I, De Visschere M, Peeters M, and Pattyn P. Noninvasive monitoring of radiotherapy-induced microvascular changes using dynamic contrast enhanced magnetic resonance imaging
(DCE-MRI) in a colorectal tumor model. Int $J$ Radiat Oncol 64: 1188-1196, 2006.

22. Coles C, Williams M, and Burnet N. Hyperbaric oxygen therapy. Combination with radiotherapy in cancer is of proved benefit but rarely used. BMJ 318: 1076-1078, 1999.

23. Couet WR, Brasch RC, Sosnovsky C, Lukszo J, Prakash I, Gnewech CT, and Tozer TN. Influerce of chemical structure of nitroxyl spin labels on their reduction by ascorbic acid. Tetrahedron 41: 1165-1172, 1985.

24. Dalle-Donne I. Biomarkers of oxidative damage in human disease. Clin Chem 52: 601-623, 2006.

25. Dewhirst MW, Ong ET, Braun RD, Smith B, Klitzman B, Evans SM, and Wilson D. Quantification of longitudinal tissue pO2 gradients in window chamber tumours: impact on tumour hypoxia. Br J Cancer 79: 1717-1722, 1999.

26. Dhimitruka I, Bobko AA, Eubank TD, Komarov DA, and Khramtsov VV. Phosphonated trityl probes for concurrent in vivo tissue oxygen and $\mathrm{pH}$ monitoring using electron paramagnetic resonance-based techniques. J Am Chem Soc 135: 5904-5910, 2013.

27. Dhimitruka I, Bobko AA, Hadad CM, Zweier JL, and Khramtsov VV. Synthesis and characterization of amino derivatives of persistent trityl radicals as dual function $\mathrm{pH}$ and oxygen paramagnetic probes. J Am Chem Soc 130: 10780-10787, 2008.

28. Dings RPM, Loren M, Heun H, McNiel E, Griffioen AW, Mayo KH, and Griffin RJ. Scheduling of radiation with angiogenesis inhibitors anginex and avastin improves therapeutic outcome via vessel normalization. Clin Cancer Res 13: 3395-3402, 2007.

29. Dreher MR, Liu W, Michelich CR, Dewhirst MW, Yuan F, and Chilkoti A. Tumor vascular permeability, accumulation, and penetration of macromolecular drug carriers. JNCI J Natl Cancer Inst 98: 335-344, 2006.

30. Dröge W. Free radicals in the physiological control of cell function. Physiol Rev 82: 47-95, 2002.

31. Eaton SS and Eaton GR. EPR imaging. J Magn Reson 59: 474-477, 1984.

32. Efimova OV, Caia GL, Sun Z, Petryakov S, Kesselring E, Samouilov A, and Zweier JL. Standard-based method for proton-electron double resonance imaging of oxygen. $J$ Magn Reson 212: 197-203, 2011.

33. Efimova OV, Sun Z, Petryakov S, Kesselring E, Caia GL, Johnson D, Zweier JL, Khramtsov VV, and Samouilov A. Variable radio frequency proton-electron doubleresonance imaging: application to $\mathrm{pH}$ mapping of aqueous samples. J Magn Reson 209: 227-232, 2011.

34. Elas M, Williams BB, Parasca A, Mailer C, Pelizzari CA, Lewis MA, River JN, Karczmar GS, Barth ED, and Halpern HJ. Quantitative tumor oxymetric images from 4D electron paramagnetic resonance imaging (EPRI): methodology and comparison with blood oxygen leveldependent (BOLD) MRI. Magn Reson Med 49: 682-691, 2003.

35. Epel B and Halpern HJ. In Vivo pO2 imaging of tumors. Methods Enzymol 564:501-527, 2015.

36. Eto H, Hyodo F, Kosem N, Kobayashi R, Yasukawa K, Nakao M, Kiniwa M, and Utsumi H. Redox imaging of skeletal muscle using in vivo DNP-MRI and its application to an animal model of local inflammation. Free Radic Biol Med 89: 1097-1104, 2015.

37. Folkman J. Fundamental concepts of the angiogenic process. Curr Mol Med 3: 643-651, 2003. 
38. Fujii $\mathrm{H}$ and Berliner LJ. One- and two-dimensional EPR imaging studies on Phantoms and Plant specimens. Magn Reson Med 2: 275-282, 1985.

39. Gallez B and Mäder K. Accurate and sensitive measurements of $\mathrm{pO}(2)$ in vivo using low frequency EPR spectroscopy: how to confer biocompatibility to the oxygen sensors. Free Radic Biol Med 29: 1078-1084, 2000.

40. Gallez B, Baudelet C, and Jordan BF. Assessment of tumor oxygenation by electron paramagnetic resonance: principles and applications. NMR Biomed 17: 240-262, 2004.

41. Gallez B, Jordan BF, Baudelet C, Misson P-D: Pharmacological modifications of the partial pressure of oxygen in murine tumors: Evaluation using in vivo EPR oximetry. Magn Reson Med 42: 627-630, 1999.

42. Giaccia. Hypoxic stress proteins: survival of the fittest. Semin Radiat Oncol 6: 46-58, 1996.

43. Gillies RJ, Raghunand N, Garcia-Martin ML, and Gatenby RA. $\mathrm{pH}$ imaging. A review of $\mathrm{pH}$ measurement methods and applications in cancers. IEEE Eng Med Biol Mag 23: 57-64.

44. Golman K, Leunbach I, Ardenkjaer-Larsen JH, Ehnholm GJ, Wistrand LG, Petersson JS, Järvi A, and Vahasalo S. Overhauser-enhanced MR imaging (OMRI). Acta Radiol 39: 10-17, 1998.

45. Golman K, Petersson JS, Ardenkjaer-Larsen JH, Leunbach I, Wistrand LG, Ehnholm G, and Liu K. Dynamic in vivo oxymetry using overhauser enhanced MR imaging. J Magn Reson Imaging 12: 929-938, 2000.

46. Gomberg M. An instance of trivalent carbon: triphenylmethyl. J Am Chem Soc 22: 757-771, 1900.

47. Grucker D. In vivo detection of injected free radicals by overhauser effect imaging. Magn Reson Med 14: 140-147, 1990.

48. Grucker D and Chambron J. Oxygen imaging in perfused hearts by dynamic nuclear polarization. Magn Reson Imaging 11: 691-696, 1993.

49. Grucker D, Guiberteau T, and Planinŝic G. Protonelectron double resonance: spectroscopy and imaging in very low magnetic fields. Res Chem Intermed 22: 567$579,1996$.

50. Halpern HJ, Yu C, Peric M, Barth ED, Karczmar GS, River JN, Grdina DJ, and Teicher BA. Measurement of differences in pO 2 in response to perfluorocarbon/carbogen in FSa and NFSa murine fibrosarcomas with low-frequency electron paramagnetic resonance oximetry. Radiat Res 145: 610, 1996.

51. Hjortdal VE, Timmenga EJ, Kjølseth D, Brink Henriksen T, Stender Hansen E, Djurhuus JC, and Gottrup F. Continuous direct tissue oxygen tension measurement. A new application for an intravascular oxygen sensor. Ann Chir Gynaecol 80: 8-13, 1991.

52. Höckel M, Schlenger K, Aral B, Mitze M, Schäffer U, Hockel M, Schlenger K, Aral B, Mitze M, Schaffer U, and Vaupel P. Association between tumor hypoxia and malignant progression in advanced cancer of the uterine cervix. Cancer Res 56: 4509-4515, 1996.

53. Hockel $M$ and Vaupel P. Tumor hypoxia: definitions and current clinical, biologic, and molecular aspects. JNCI J Natl Cancer Inst 93: 266-276, 2001.

54. Hofer SOP, Timmenga EJF, Christiano R, and Bos KE. An intravascular oxygen tension monitoring device used in myocutaneous transplants: a preliminary report. Microsurgery 14: 304-309, 1993.
55. Horsman MR, Nordsmark M, and Overgaard J. Techniques to assess the oxygenation of human tumors. State of the art. Strahlenther Onkol 174 Suppl: 2-5, 1998.

56. Hyodo F, Ito S, Yasukawa K, Kobayashi R, and Utsumi H. Simultaneous and spectroscopic redox molecular imaging of multiple free radical intermediates using dynamic nuclear polarization-magnetic resonance imaging. Anal Chem 86: 7234-7238, 2014.

57. Hyodo F, Murugesan R, Matsumoto K, Hyodo E, Subramanian S, Mitchell JB, and Krishna MC. Monitoring redox-sensitive paramagnetic contrast agent by EPRI, OMRI and MRI. J Magn Reson 190: 105-112, 2008.

58. Iannone A, Tomasi A, Vannini V, and Swartz HM. Metabolism of nitroxide spin labels in subcellular fraction of rat liver. I. Reduction by microsomes. Biochim Biophys Acta 1034: 285-289, 1990.

59. Iannone A, Tomasi A, Vannini V, and Swartz HM. Metabolism of nitroxide spin labels in subcellular fractions of rat liver. II. Reduction in the cytosol. Biochim Biophys Acta 1034: 290-293, 1990.

60. Ichiwata T, Sasao G, Abe T, Kikuchi K, Koyama K, Fujiwara H, Nagai A, Kuwahira I, and Nagao K. Oxidative capacity of the skeletal muscle and lactic acid kinetics during exercise in healthy subjects and patients with COPD. Adv Exp Med Biol 662: 537-543, 2010.

61. Jain RK. Lessons from multidisciplinary translational trials on anti-angiogenic therapy of cancer. Nat Rev Cancer 8: 309-316, 2008.

62. Jain RK. Molecular regulation of vessel maturation. Nat Med 9: 685-693, 2003.

63. Jain RK. Normalizing tumor vasculature with anti-angiogenic therapy: a new paradigm for combination therapy. Nat Med 7: 987-989, 2001.

64. Jenner P. Oxidative stress in Parkinson's disease. Ann Neurol 53: S26-S38, 2003.

65. Kaiser R. Use of the nuclear overhauser effect in the analysis of high-resolution nuclear magnetic resonance spectra. J Chem Phys 39: 2435-2442, 1963.

66. Kashiwagi S, Tsukada K, Xu L, Miyazaki J, Kozin S V, Tyrrell JA, Sessa WC, Gerweck LE, Jain RK, and Fukumura D. Perivascular nitric oxide gradients normalize tumor vasculature. Nat Med 14: 255-257, 2008.

67. Khan N, Williams BB, Hou H, Li H, and Swartz HM. Repetitive tissue pO 2 measurements by electron paramagnetic resonance oximetry: current status and future potential for experimental and clinical studies. Antioxid Redox Signal 9: 1169-1182, 2007.

68. Khramtsov VV, Bobko AA, Tseytlin M, and Driesschaert B. Exchange phenomena in the electron paramagnetic resonance spectra of the nitroxyl and trityl radicals: multifunctional spectroscopy and imaging of local chemical microenvironment. Anal Chem 89: 4758-4771, 2017.

69. Khramtsov VV, Caia GL, Shet K, Kesselring E, Petryakov S, Zweier JL, and Samouilov A. Variable field protonelectron double-resonance imaging: application to $\mathrm{pH}$ mapping of aqueous samples. J Magn Reson 202: 267$273,2010$.

70. Khramtsov VV, Grigor'ev IA, Foster MA, Lurie DJ, and Nicholson I. Biological applications of spin $\mathrm{pH}$ probes. Cell Mol Biol (Noisy-le-grand) 46: 1361-1374, 2000.

71. Kinoshita Y, Yamada K-I, Yamasaki T, Sadasue H, Sakai $\mathrm{K}$, and Utsumi H. Development of novel nitroxyl radicals for controlling reactivity with ascorbic acid. Free Radic Res 43: 565-571, 2009. 
72. Kosem N, Naganuma T, Ichikawa K, Phumala Morales N, Yasukawa K, Hyodo F, Yamada K, and Utsumi H. Wholebody kinetic image of a redox probe in mice using Overhauser-enhanced MRI. Free Radic Biol Med 53: 328-336, 2012.

73. Kraig RP, Petito CK, Plum F, and Pulsinelli WA. Hydrogen ions kill brain at concentrations reached in ischemia. J Cereb Blood Flow Metab 7: 379-386, 1987.

74. Kraut JA and Madias NE. Consequences and therapy of the metabolic acidosis of chronic kidney disease. Pediatr Nephrol 26: 19-28, 2011.

75. Krishna MC, English S, Yamada K, Yoo J, Murugesan R, Devasahayam N, Cook JA, Golman K, Ardenkjaer-Larsen $\mathrm{JH}$, Subramanian S, and Mitchell JB. Overhauser enhanced magnetic resonance imaging for tumor oximetry: coregistration of tumor anatomy and tissue oxygen concentration. Proc Natl Acad Sci U S A 99: 2216-2221, 2002.

76. Krishna MC, Russo A, Mitchell JB, Goldstein S, Dafni H, and Samuni A. Do nitroxide antioxidants act as scavengers of O2-. or as SOD mimics? J Biol Chem 271: 2602626031, 1996.

77. Lagrota-Candido J, Canella I, Pinheiro DF, Santos-Silva LP, Ferreira RS, Guimarães-Joca FJ, Lannes-Vieira J, and Quirico-Santos T. Characteristic pattern of skeletal muscle remodelling in different mouse strains. Int J Exp Pathol 91: 522-529, 2010.

78. Lurie DJ. Progress toward whole-body proton-electron double-resonance imaging of free radicals. Magma Magn Reson Mater Phys Biol Med 2: 267-271, 1994.

79. Lurie DJ, Bussell DM, Bell LH, and Mallard JR. Protonelectron double magnetic resonance imaging of free radical solutions. J Magn Reson 76: 366-370, 1988.

80. Lurie DJ, Davies GR, Foster MA, Hutchison JMS. Fieldcycled PEDRI imaging of free radicals with detection at 450 mT. Magn Reson Imaging 23: 175-181, 2005.

81. Lurie DJ, Foster MA, Yeung D, Hutchison JMS: Design, construction and use of a large-sample field-cycled PEDRI imager. Phys Med Biol 43: 1877-1886, 1998.

82. Lurie DJ, Hutchison JM, Bell LH, Nicholson I, Bussell DM, and Mallard JR. Field-cycled proton-electron doubleresonance imaging of free radicals in large aqueous samples. J Magn Reson 84: 431-437, 1989.

83. Lurie DJ, Li H, Petryakov S, and Zweier JL. Development of a PEDRI free-radical imager using a $0.38 \mathrm{~T}$ clinical MRI system. Magn Reson Med 47: 181-186, 2002.

84. Mallard JR and Kent M. Electron spin resonance in surviving rat tissues. Nature 210: 588-591, 1966.

85. Maltempo MM, Eaton SS, and Eaton GR. Spectral-spatial two-dimensional EPR imaging. J Magn Reson 72: 449455, 1987.

86. Maritim AC, Sanders RA, and Watkins JB. Diabetes, oxidative stress, and antioxidants: a review. J Biochem Mol Toxicol 17: 24-38, 2003.

87. Markesbery WR. Oxidative stress hypothesis in Alzheimer's disease. Free Radic Biol Med 23: 134-147, 1997.

88. Mason RP, Jeffrey FMH, Malloy CR, Babcock EE, and Antich PP. A noninvasive assessment of myocardial oxygen tension:19F NMR spectroscopy of sequestered perfluorocarbon emulsion. Magn Reson Med 27: 310-317, 1992.

89. Mateescu GD and Cabrera ME. In vivo 170 magnetic resonance spectroscopy. Determination of temperature effects on metabolic rates (Q10 factor). Adv Exp Med Biol 411: 585-590, 1997.
90. Matsumoto K, Hyodo F, Anzai K, Utsumi H, Mitchell JB, and Krishna MC. Brain redox imaging. Methods Mol Biol 711: 397-419, 2011.

91. Matsumoto S, Hyodo F, Subramanian S, Devasahayam N, Munasinghe J, Hyodo E, Gadisetti C, Cook JA, Mitchell $\mathrm{JB}$, and Krishna MC. Low-field paramagnetic resonance imaging of tumor oxygenation and glycolytic activity in mice. J Clin Invest 118: 1965-1973, 2008.

92. Matsumoto S, Utsumi H, Aravalluvan T, Matsumoto K-I, Matsumoto A, Devasahayam N, Sowers AL, Mitchell JB, Subramanian S, and Krishna MC. Influence of proton T1 on oxymetry using Overhauser enhanced magnetic resonance imaging. Magn Reson Med 54: 213-217, 2005.

93. Matsumoto S, Yasui H, Batra S, Kinoshita Y, Bernardo M, Munasinghe JP, Utsumi H, Choudhuri R, Devasahayam N, Subramanian S, Mitchell JB, and Krishna MC. Simultaneous imaging of tumor oxygenation and microvascular permeability using Overhauser enhanced MRI. Proc Natl Acad Sci U S A 106: 17898-17903, 2009.

94. Maxwell PH, Dachs GU, Gleadle JM, Nicholls LG, Harris AL, Stratford IJ, Hankinson O, Pugh CW, and Ratcliffe PJ. Hypoxia-inducible factor-1 modulates gene expression in solid tumors and influences both angiogenesis and tumor growth. Proc Natl Acad Sci U S A 94: 8104-8109, 1997.

95. Naumov GN, Akslen LA, and Folkman J. Role of Angiogenesis in human tumor dormancy: animal models of the angiogenic switch. Cell Cycle 5: 1779-1787, 2006.

96. Ndubuizu O and LaManna JC. Brain tissue oxygen concentration measurements. Antioxid Redox Signal 9: 12071220, 2007.

97. Neveu M-A, Joudiou N, De Preter G, Dehoux J-P, Jordan $\mathrm{BF}$, and Gallez B. ${ }^{17} \mathrm{O}$ MRS assesses the effect of mild hypothermia on oxygen consumption rate in tumors. NMR Biomed 30: e3726, 2017.

98. Niwano $\mathrm{S}$ and Tojo T. Systemic acidosis in acute myocardial ischemia - cause or result of life-threateningventricular arrhythmia? Circ J 74: 1794-1795, 2010.

99. Noseworthy MD, Bulte DP, and Alfonsi J. BOLD magnetic resonance imaging of skeletal muscle. Semin Musculoskelet Radiol 7: 307-316, 2003.

100. Overhauser AW. Polarization of nuclei in metals. Phys Rev 92: 411-415, 1953.

101. Parhami P and Fung BM. Fluorine-19 relaxation study of perfluoro chemicals as oxygen carriers. J Phys Chem 87: 1928-1931, 1983.

102. Potapenko DI, Foster MA, Lurie DJ, Kirilyuk IA, Hutchison JMS, Grigor'ev IA, Bagryanskaya EG, and Khramtsov VV. Real-time monitoring of drug-induced changes in the stomach acidity of living rats using improved $\mathrm{pH}$-sensitive nitroxides and low-field EPR techniques. J Magn Reson 182: 1-11, 2006.

103. Quintanilha AT and Packer L. Surface localization of sites of reduction of nitroxide spin-labeled molecules in mitochondria. Proc Natl Acad Sci U S A 74: 570-574, 1977.

104. Rasey JS, Koh WJ, Evans ML, Peterson LM, Lewellen TK, Graham MM, and Krohn KA. Quantifying regional hypoxia in human tumors with positron emission tomography of $[18 \mathrm{~F}]$ fluoromisonidazole: a pretherapy study of 37 patients. Int J Radiat Oncol Biol Phys 36: 417-428, 1996. 
105. Reddy TJ, Iwama T, Halpern HJ, and Rawal VH. General synthesis of persistent trityl radicals for EPR imaging of biological systems. J Org Chem 67: 4635-4639, 2002.

106. Ribeiro PD, Sanches MG, and Okamoto T. Comparative analysis of tissue reactions to anesthetic solutions: histological analysis in subcutaneous tissue of rats. Anesth Prog 50: 169-180, 2003.

107. Robinson SP and Griffiths JR. Current issues in the utility of $19 \mathrm{~F}$ nuclear magnetic resonance methodologies for the assessment of tumour hypoxia. Philos Trans R Soc B Biol Sci 359: 987-996, 2004.

108. Samouilov A, Efimova O V, Bobko AA, Sun Z, Petryakov S, Eubank TD, Trofimov DG, Kirilyuk IA, Grigor'ev IA, Takahashi W, Zweier JL, and Khramtsov VV. In vivo proton-electron double-resonance imaging of extracellular tumor $\mathrm{pH}$ using an advanced nitroxide probe. Anal Chem 86: 1045-1052, 2014.

109. Sano H, Naruse M, Matsumoto K, Oi T, and Utsumi H. A new nitroxyl-probe with high retention in the brain and its application for brain imaging. Free Radic Biol Med 28: 959-969, 2000.

110. Schwarz PF, Turro NJ, Bossmann SH, Braun AM, Wahab A-MAA, and Dürr H. A new method to determine the generation of hydroxyl radicals in illuminated $\mathrm{TiO} 2$ suspensions. J Phys Chem B 101: 7127-7134, 1997.

111. Seimenis I, Foster MA, Lurie DJ, Hutchison JMS, Whiting $\mathrm{PH}$, and Payne $\mathrm{S}$. The excretion mechanism of the spin label proxyl carboxylic acid (PCA) from the rat monitored by X-band ESR and PEDRI. Magn Reson Med 37: 552$558,1997$.

112. Shiba T, Yamato M, Kudo W, Watanabe T, Utsumi H, and Yamada K. In vivo imaging of mitochondrial function in methamphetamine-treated rats. Neuroimage 57: 866-872, 2011 .

113. Singh U and Jialal I. Oxidative stress and atherosclerosis. Pathophysiology 13: 129-142, 2006.

114. Spasojević I. Electron paramagnetic resonance-a powerful tool of medical biochemistry in discovering mechanisms of disease and treatment prospects. J Med Biochem 29, 175-188, 2010.

115. Stratford IJ, Adams GE, Bremner JC, Cole S, Edwards HS, Robertson N, and Wood PJ. Manipulation and exploitation of the tumour environment for therapeutic benefit. Int J Radiat Biol 65: 85-94, 1994.

116. Su MY, Mühler A, Lao X, and Nalcioglu O. Tumor characterization with dynamic contrast-enhanced MRI using MR contrast agents of various molecular weights. Magn Reson Med 39: 259-269, 1998.

117. Subczynski WK, Lukiewicz S, and Hyde JS. Murine in vivo L-band ESR spin-label oximetry with a loop-gap resonator. Magn Reson Med 3: 747-754, 1986.

118. Subramanian S, Matsumoto K-I, Mitchell JB, and Krishna MC. Radio frequency continuous-wave and time-domain EPR imaging and Overhauser-enhanced magnetic resonance imaging of small animals: instrumental developments and comparison of relative merits for functional imaging. NMR Biomed 17: 263-294, 2004.

119. Sven Andersson, Finn Radner, Anna Rydbeek, Rolf Servin, and Lars-Goran Wistrand. US5530140A-US Patents., 1996.

120. Swartz HM and Clarkson RB. The measurement of oxygen in vivo using EPR techniques. Phys Med Biol 43: 1957-1975, 1998.
121. Swartz HM, Sentjurc M, and Morse PD. Cellular metabolism of water-soluble nitroxides: effect on rate of reduction of cell/nitroxide ratio, oxygen concentrations and permeability of nitroxides. Biochim Biophys Acta Mol Cell Res 888: 82-90, 1986.

122. Takahashi W, Bobko AA, Dhimitruka I, Hirata H, Zweier JL, Samouilov A, and Khramtsov VV. Proton-electron double-resonance imaging of ph using phosphonated trityl probe. Appl Magn Reson 45: 817-826, 2014.

123. Utsumi $\mathrm{H}$ and Hyodo F. Free Radical Imaging Using In Vivo Dynamic Nuclear Polarization-MRI. Methods Enzymol 564: 553-571, 2015.

124. Utsumi H, Shimakura A, Kashiwagi M, and Hamada A. Localization of the active center of nitroxide radical reduction in rat liver microsomes: its relation to cytochrome P-450 and membrane fluidity. J Biochem 105: 239-244, 1989.

125. Utsumi H, Yamada K-I, Ichikawa K, Sakai K, Kinoshita Y, Matsumoto S, and Nagai M. Simultaneous molecular imaging of redox reactions monitored by Overhauserenhanced MRI with $14 \mathrm{~N}$ - and $15 \mathrm{~N}$-labeled nitroxyl radicals. Proc Natl Acad Sci U S A 103: 1463-1468, 2006.

126. Vaupel P. Oxygenation status of malignant tumors: pathogenesis of hypoxia and significance for tumor therapy. Semin Oncol 28: 29-35, 2001.

127. Vaupel P, Schlenger K, and Hoeckel M. Blood flow and tissue oxygenation of human tumors: an update. Adv Exp Med Biol 317: 139-151, 1992.

128. Velan SS, Spencer RG, Zweier JL, and Kuppusamy P. Electron paramagnetic resonance oxygen mapping (EPROM): direct visualization of oxygen concentration in tissue. Magn Reson Med 43: 804-809, 2000.

129. Voest EE, van Faassen E, and Marx JJ. An electron paramagnetic resonance study of the antioxidant properties of the nitroxide free radical TEMPO. Free Radic Biol Med 15: 589-595, 1993.

130. Wagner K, Bossen W, and Schramm U. Tissue alterations by the penetration of a PO2 sensing needle probe. Adv Exp Med Biol 317: 639-644, 1992.

131. Williams BB, al Hallaq H, Chandramouli GVR, Barth ED, Rivers JN, Lewis M, Galtsev VE, Karczmar GS, and Halpern HJ. Imaging spin probe distribution in the tumor of a living mouse with $250 \mathrm{MHz}$ EPR: Correlation with BOLD MRI. Magn Reson Med 47: 634-638, 2002.

132. Woitzik J, Back T, and Thome C. Flow-dependent versus spreading-like impairment of brain tissue integrity during focal cerebral ischemia and its consequences for neuroprotective strategies. Front Biosci 13: 1500-1506, 2008.

133. Yamato M, Shiba T, Naganuma T, Ichikawa K, Utsumi H, and Yamada K. Overhauser-enhanced magnetic resonance imaging characterization of mitochondria functional changes in the 6-hydroxydopamine rat model. Neurochem Int 59: 804-811, 2011.

134. Yong L, Harbridge J, Quine RW, Rinard GA, Eaton SS, Eaton GR, Mailer C, Barth E, and Halpern HJ. Electron spin relaxation of triarylmethyl radicals in fluid solution. $J$ Magn Reson 152: 156-161, 2001.

135. Zhang X, Lin Y, and Gillies RJ. Tumor $\mathrm{pH}$ and its measurement. J Nucl Med 51: 1167-1170, 2010.

136. Zhu X-H, Zhang Y, Wiesner HM, Ugurbil K, and Chen $\mathrm{W}$. In vivo measurement of CBF using ${ }^{17} \mathrm{O}$ NMR signal of metabolically produced $\mathrm{H}_{2}{ }^{17} \mathrm{O}$ as a perfusion tracer. Magn Reson Med 70: 309-314, 2013. 
137. Zweier JL, Thompson-Gorman S, and Kuppusamy P. Measurement of oxygen concentrations in the intact beating heart using electron paramagnetic resonance spectroscopy: a technique for measuring oxygen concentrations in situ. J Bioenerg Biomembr 23: 855-871, 1991.

Address correspondence to: Prof. David J. Lurie

School of Medicine, Medical Sciences \& Nutrition

University of Aberdeen

Aberdeen AB25 2ZD

United Kingdom

E-mail: d.lurie@abdn.ac.uk

Date of first submission to ARS Central, September 4, 2017; date of acceptance, October 5, 2017.

\section{Abbreviations Used}

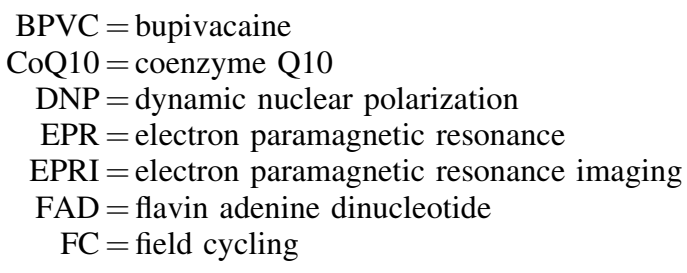

FMN = flavin mononucleotide

Gd-DTPA = gadolinium-diethylenetriamine pentaacetic acid

hfs = hyperfine splitting

$\mathrm{HOPE}=$ trityl probe with spectral sensitivity to $\mathrm{pH}, \mathrm{pO}_{2}$, and $\mathrm{Pi}$ (inorganic phosphate) in extracellular tissue microenvironment

MC-PROXYL = 3-MethoxyCarbonyl-2,2,5,5-Tetramethylpyrrolidine-1-yloxy

MRI = magnetic resonance imaging

$\mathrm{NMR}=$ nuclear magnetic resonance

$\mathrm{NOE}=$ nuclear Overhauser effect

OMRI = Overhauser-enhanced magnetic resonance imaging

PCA $=$ proxyl carboxylic acid

PEDRI $=$ proton-electron double-resonance imaging

$\mathrm{pO}_{2}=$ partial pressure of oxygen

$\mathrm{RF}=$ radio frequency

$\mathrm{ROI}=$ region of interest

$\mathrm{SAR}=$ specific absorption rate

$\mathrm{SNR}=$ signal-to-noise ratio

TAM $=$ triarylmethyl or trityl radical

TEMPO $=2,2,6,6$-tetramethyl-1-piperidinyloxy

TEMPOL $=$ 4-hydroxy-2,2,6,6-tetramethylpiperidine1-oxyl

$\mathrm{TME}=$ tumor tissue microenvironment

$\mathrm{VF}=$ variable field

$\mathrm{VRF}=$ variable radio frequency 